Dennis Wiedemann, Suliman Nakhal, Alexandra Franz, Martin Lerch

\title{
Lithium diffusion pathways in metastable ramsdellite-like Li2Ti3O7 from high- temperature neutron diffraction
}

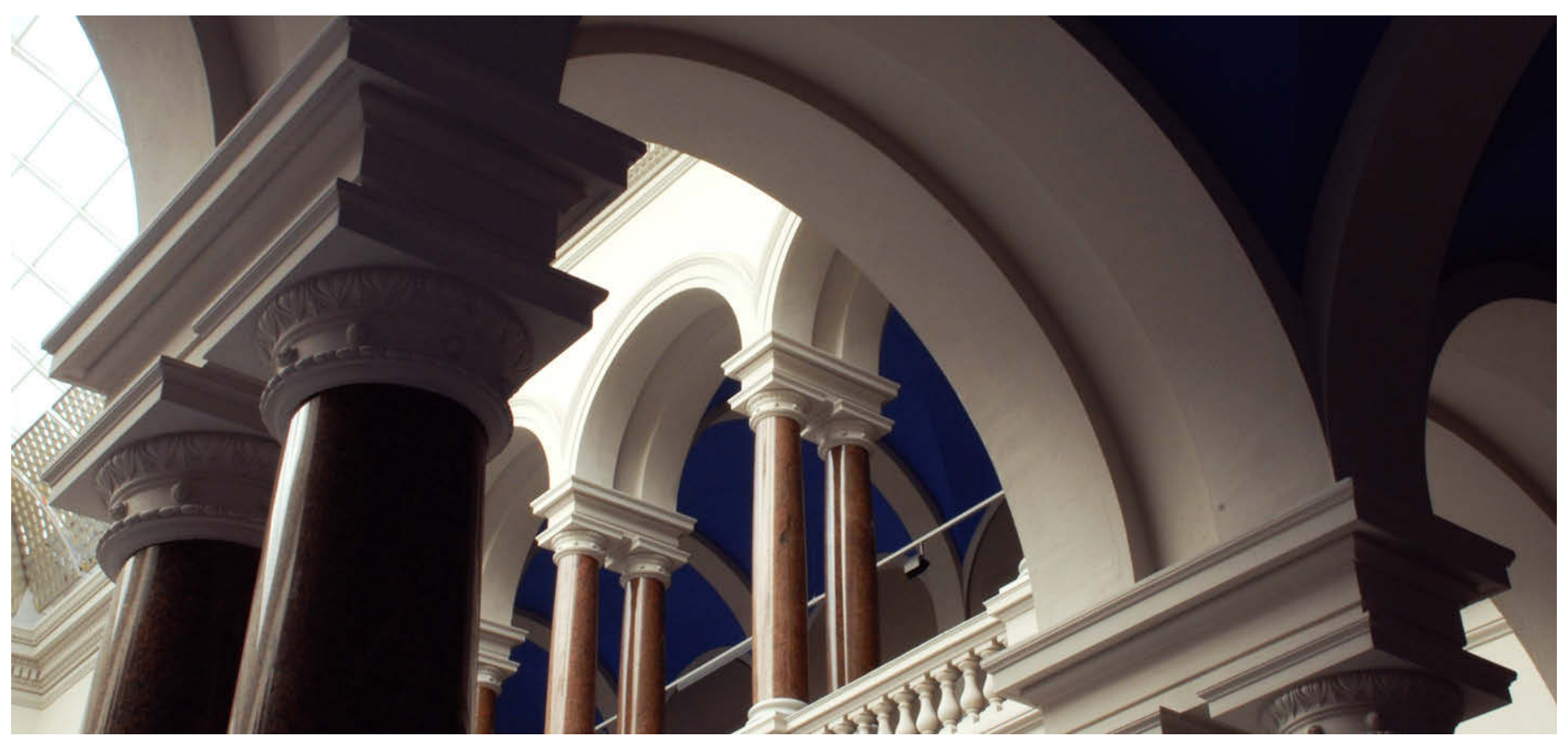

\section{Suggested Citation}

Wiedemann, Dennis et al.: Lithium diffusion pathways in metastable ramsdellite-like Li2Ti3O7 from hightemperature neutron diffraction. - Solid state ionics : diffusion and reactions. - ISSN: 0167-2738 (print), 1872-7689 (online). - 293 (2016), October. - pp. 37-43. - DOI: 10.1016/j.ssi.2016.06.002. (Postprint version is cited, page numbers differ.) 


\title{
Lithium Diffusion Pathways in Metastable Ramsdellite- Like $\mathrm{Li}_{2} \mathrm{Ti}_{3} \mathrm{O}_{7}$ from High-Temperature Neutron Diffraction
}

Dennis Wiedemann ${ }^{a} *$, Suliman Nakhal ${ }^{a}$, Alexandra Franz ${ }^{b}$, Martin Lerch $^{a}$

${ }^{a}$ Institut für Chemie, Technische Universität Berlin, Straße des 17. Juni 135, 10623 Berlin, Germany

b Abteilung Struktur und Dynamik von Energiematerialien, Helmholtz-Zentrum Berlin für Materialien und Energie, Hahn-Meitner-Platz 1, 14109 Berlin, Germany

\begin{abstract}
Ramsdellite-like $\mathrm{Li}_{2} \mathrm{Ti}_{3} \mathrm{O}_{7}$ is an excellent, strongly anisotropic lithium-ion conductor with various proposed applications in energy storage and lithium processing. Diffusion pathways have not yet been thoroughly studied, in spite of their importance for these purposes; even the precise crystal structure of this material is a subject of ongoing discussion. Herein, we use variable-temperature neutron diffraction in the metastability range of ramsdellite-like $\mathrm{Li}_{2} \mathrm{Ti}_{3} \mathrm{O}_{7}$ to probe the nontrivial lithium-ion distribution. Refinement with anisotropic displacement parameters including anharmonic terms identifies the room-temperature structure as statically disordered snapshot of the dynamic behavior at synthesis temperature. Mapping of scattering-length density, reconstructed using maximum-entropy methods (MEM), shows the signature of partial relaxation and activation of lithium movement with increasing temperature. Scrutinous topological analyses of procrystal voids and Voronoi-Dirichlet partitioning (VDP) reveal lithium diffusion along ribbons in the interstitial channels as the major and diffusion through framework vacancies as the most probable minor mechanism. By rationalizing former empirical results, we provide deeper insight into this paradigmatic example of strongly anisotropic lithium-ion conductors.
\end{abstract}

\section{Keywords}

Dilithium trititanate; Lithium migration; Neutron powder diffraction; Voronoi-Dirichlet partitioning; Procrystal void surface; Maximum-entropy methods

\section{Introduction}

The most common polymorph of dilithium trititanium heptoxide (dilithium trititanate) was synthesized by Jonker in 1957 for the first time [1], assigned a ramsdellite-like structure by Lundberg and Andersson in 1964 [2], and structurally elucidated using single-crystal X-ray diffraction by Morosin and Mikkelsen in 1979 [3]. The term "ramsdellite-like" refers to the mineral name of $\gamma$ - $\mathrm{MnO}_{2}$, the structure of which was determined by Byström in 1949 [4] and slightly corrected in 1995 [5]. This form of $\mathrm{Li}_{2} \mathrm{Ti}_{3} \mathrm{O}_{7}$ (formerly called $\mathrm{R}-\mathrm{Li}_{2} \mathrm{Ti}_{3} \mathrm{O}_{7}$ ) is often stated to be of the "ramsdellite type", whereasaccording to recommendations by the International Union of Crystallography (IUCr) [6] -its structure should be designated as a "stuffed derivative of the $\mathrm{VO}_{2}$ type". Ramsdellite-like $\mathrm{Li}_{2} \mathrm{Ti}_{3} \mathrm{O}_{7}$ adopts the space group Pnma, but is mostly set in the non-standard Pbnm for reasons of tradition (Byström's

\footnotetext{
${ }^{*}$ Corresponding author. E-mail address: dennis.wiedemann@chem.tu-berlin.de (D. Wiedemann).
} 


\title{
Lithium Diffusion Pathways in Metastable Ramsdellite- Like $\mathrm{Li}_{2} \mathrm{Ti}_{3} \mathrm{O}_{7}$ from High-Temperature Neutron Diffraction
}

Dennis Wiedemann ${ }^{a} *$, Suliman Nakhal ${ }^{a}$, Alexandra Franz ${ }^{b}$, Martin Lerch $^{a}$

${ }^{a}$ Institut für Chemie, Technische Universität Berlin, Straße des 17. Juni 135, 10623 Berlin, Germany

b Abteilung Struktur und Dynamik von Energiematerialien, Helmholtz-Zentrum Berlin für Materialien und Energie, Hahn-Meitner-Platz 1, 14109 Berlin, Germany

\begin{abstract}
Ramsdellite-like $\mathrm{Li}_{2} \mathrm{Ti}_{3} \mathrm{O}_{7}$ is an excellent, strongly anisotropic lithium-ion conductor with various proposed applications in energy storage and lithium processing. Diffusion pathways have not yet been thoroughly studied, in spite of their importance for these purposes; even the precise crystal structure of this material is a subject of ongoing discussion. Herein, we use variable-temperature neutron diffraction in the metastability range of ramsdellite-like $\mathrm{Li}_{2} \mathrm{Ti}_{3} \mathrm{O}_{7}$ to probe the nontrivial lithium-ion distribution. Refinement with anisotropic displacement parameters including anharmonic terms identifies the room-temperature structure as statically disordered snapshot of the dynamic behavior at synthesis temperature. Mapping of scattering-length density, reconstructed using maximum-entropy methods (MEM), shows the signature of partial relaxation and activation of lithium movement with increasing temperature. Scrutinous topological analyses of procrystal voids and Voronoi-Dirichlet partitioning (VDP) reveal lithium diffusion along ribbons in the interstitial channels as the major and diffusion through framework vacancies as the most probable minor mechanism. By rationalizing former empirical results, we provide deeper insight into this paradigmatic example of strongly anisotropic lithium-ion conductors.
\end{abstract}

\section{Keywords}

Dilithium trititanate; Lithium migration; Neutron powder diffraction; Voronoi-Dirichlet partitioning; Procrystal void surface; Maximum-entropy methods

\section{Introduction}

The most common polymorph of dilithium trititanium heptoxide (dilithium trititanate) was synthesized by Jonker in 1957 for the first time [1], assigned a ramsdellite-like structure by Lundberg and Andersson in 1964 [2], and structurally elucidated using single-crystal X-ray diffraction by Morosin and Mikkelsen in 1979 [3]. The term "ramsdellite-like" refers to the mineral name of $\gamma$ - $\mathrm{MnO}_{2}$, the structure of which was determined by Byström in 1949 [4] and slightly corrected in 1995 [5]. This form of $\mathrm{Li}_{2} \mathrm{Ti}_{3} \mathrm{O}_{7}$ (formerly called $\mathrm{R}-\mathrm{Li}_{2} \mathrm{Ti}_{3} \mathrm{O}_{7}$ ) is often stated to be of the "ramsdellite type", whereasaccording to recommendations by the International Union of Crystallography (IUCr) [6] -its structure should be designated as a "stuffed derivative of the $\mathrm{VO}_{2}$ type". Ramsdellite-like $\mathrm{Li}_{2} \mathrm{Ti}_{3} \mathrm{O}_{7}$ adopts the space group Pnma, but is mostly set in the non-standard Pbnm for reasons of tradition (Byström's

\footnotetext{
${ }^{*}$ Corresponding author. E-mail address: dennis.wiedemann@chem.tu-berlin.de (D. Wiedemann).
} 
structure determination). The relation of the $\mathrm{Li}_{2} \mathrm{Ti}_{3} \mathrm{O}_{7}$ structure with the $\mathrm{Li}_{0.5} \mathrm{TiO}_{2}$ type, often being assigned to it, is rather one of homeotypism by defects than of real isotypism.

Nonetheless, any of these terms is used to distinguish the common polymorph from two others: a layered one $\left(P 2_{1} / m, \mathrm{Li}_{2} \mathrm{Ti}_{3} \mathrm{O}_{7}\right.$ type, isopointal to $\mathrm{Na}_{2} \mathrm{Ti}_{3} \mathrm{O}_{7}$ type), which was first prepared in 1985 [7] and described in detail in 2008 [8], and a hexagonal one (also called $\mathrm{H}-\mathrm{Li}_{2} \mathrm{Ti}_{3} \mathrm{O}_{7}, R 3 c$ ), which was first observed in 1980 [9] and structurally elucidated in 2000 [10]. The pseudo-binary system $\mathrm{Li}_{2} \mathrm{O}-\mathrm{TiO}_{2}$ containing titanium(IV) compounds only is governed by stable phases of the compositions $\mathrm{Li}_{4} \mathrm{TiO}_{4}$, $\mathrm{Li}_{2} \mathrm{TiO}_{3}, \mathrm{Li}_{4} \mathrm{Ti}_{5} \mathrm{O}_{12}$, and $\mathrm{Li}_{2} \mathrm{Ti}_{3} \mathrm{O}_{7}$. Ramsdellite-like $\mathrm{Li}_{2} \mathrm{Ti}_{3} \mathrm{O}_{7}$ is thermodynamically stable from 950 to $1300{ }^{\circ} \mathrm{C}$ and melts above. By quenching, it can be sustained in a metastable state below this interval. Upon heating from room temperature (r.t.), it is said to transform into the hexagonal polymorph around $630{ }^{\circ} \mathrm{C}$ [11], which decomposes into spinel-like $\mathrm{Li}_{4} \mathrm{Ti}_{5} \mathrm{O}_{12}$ and $\mathrm{TiO}_{2}$ at $c a .800{ }^{\circ} \mathrm{C}$ [9].

All of the following considerations refer to ramsdellite-like $\mathrm{Li}_{2} \mathrm{Ti}_{3} \mathrm{O}_{7}$ in its standard Pnma setting. $\mathrm{Li}_{2} \mathrm{Ti}_{3} \mathrm{O}_{7}$ (or, with $Z=1, \mathrm{Li}_{2.286} \mathrm{Ti}_{3.429} \mathrm{O}_{8}$ ) can formally be divided into a framework, adopting a cation defective or site-ordering variant of the $\mathrm{VO}_{2}$ type, and interstitial lithium ions. Although the distribution of lithium ions between framework and interstitials has been assessed differently in the past, there seems to be good reason to formulate $\left[\mathrm{Li}_{2} \square_{5}\right]_{\mathrm{i}}\left[\left(\mathrm{Ti}_{3} \square_{0.5}\right) \mathrm{O}_{7}\right]_{\mathrm{f}}$ (口: vacancy, i: interstitial, f: framework) rather than $\left[\mathrm{Li}_{1.5} \square_{5.5}\right]_{\mathrm{i}}\left[\left(\mathrm{Li}_{0.5} \mathrm{Ti}_{3}\right) \mathrm{O}_{7}\right]_{\mathrm{f}}[12,13]$. The framework consists of $M \mathrm{O}_{6}$ octahedra $(M=\mathrm{Ti}$, $\mathrm{Li}, \mathrm{\square}$ ) sharing edges to form infinite chains along $b$. Again by edge-sharing, these chains are organized in pairs, which connect to the adjacent ones via common vertices. This leaves spacious channels along $b$ hosting the interstitial lithium ions (see Fig. 1). Available neutron-diffraction studies differ in the assignment of their positions: two tetrahedrally coordinated $4 c$ sites are discussed [14-16] and one of them may split in two $8 d$ sites [17]. Taking all of these positions and those in the framework into account, lithiation of $\mathrm{Li}_{2} \mathrm{Ti}_{3} \mathrm{O}_{7}$ may lead to a theoretical maximum of two additional ions per formula unit (i.e., 2.286 ions per unit cell) under reduction of titanium(IV) to titanium(III) [18]. Chemically, 0.5/1.0 ions per formula unit can be intercalated at r.t. $/ 50^{\circ} \mathrm{C}$, respectively [19]. Electrochemical lithiation, however, can add two ions under conservation of the ramsdellite-like structure. A maximum of $c a$. 2.24 intercalated ions per formula unit is possible, but accompanied by a phase transformation [20, 21].
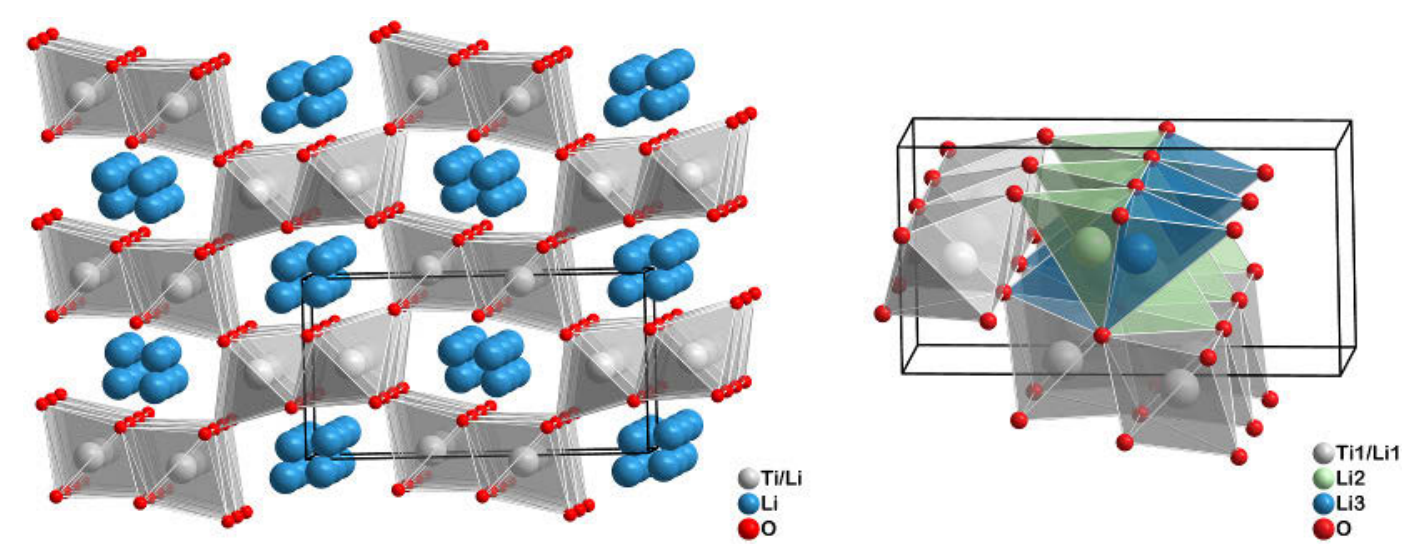

Fig. 1. Crystal structure of ramsdellite-like $\mathrm{Li}_{2} \mathrm{Ti}_{3} \mathrm{O}_{7}$ in general view (left) and channel detail (right). View approximately along $b$, ions with arbitrary radii, unit cell in black.

A most recent computational study states that " $\mathrm{Li}_{2} \mathrm{Ti}_{3} \mathrm{O}_{7}$ appears to be a (quasi) one-dimensional Liion conductor" [22] and there is indeed ample evidence to consider it preferentially one-dimensional. Early conductivity and impedance measurements on oriented single-crystals have yielded the prefactor tensor $\boldsymbol{\sigma}_{0}$ of ionic conductivity [23]: 


$$
\sigma_{0}=10^{3} \Omega^{-1} \mathrm{~cm}^{-1} \mathrm{~K} \cdot\left(\begin{array}{ccc}
29.2 & 0 & 0 \\
0 & 194.4 & 0 \\
0 & 0 & 7.7
\end{array}\right)
$$

The activation energies $E_{\mathrm{a}}$ for ion conduction in the principal crystallographic directions scatter only slightly between 0.44 and $0.47 \mathrm{eV}(0.41-0.50 \mathrm{eV}$, according to later studies [24-26]). This implies a high fractional anisotropy (FA) of $c a$. 0.90 - a quantity that can adopt values between 0 for the isotropic and 1 for the strictly one-dimensional case [27]. Probability considerations [23] and vibrational spectroscopy [28] hint at hops from an interstitial lithium site to an empty adjacent one in the channel or the framework as conduction mechanism along $b$ or $a$, respectively. However, the associated diffusion pathways have not yet been mapped or studied in depth. This fact is especially surprising, as they play a major role in most of the proposed applications, ranging from electrode material for batteries $[15,29]$ and supercapacitors [30] to matrix for lithium-isotope separation [26] and recovery of lithium from scrap alloys [10].

In this study, we present the results of neutron powder diffraction on ramsdellite-like $\mathrm{Li}_{2} \mathrm{Ti}_{3} \mathrm{O}_{7}$ at ambient and high temperatures. We settle the question of framework occupation by lithium ions, derive the most probable pathways for their diffusion, and explain the observed anisotropy of conductivity using a mixed approach: topological analyses and mapping of the scattering-length density (SLD) reconstructed using maximum-entropy methods (MEM).

\section{Experimental}

\subsection{Synthesis}

$\mathrm{Li}_{2} \mathrm{Ti}_{3} \mathrm{O}_{7}$ was prepared by solid-state synthesis according to a modified literature procedure [19]. $\mathrm{Li}_{2} \mathrm{CO}_{3}$ (Aldrich, 99.997\%) and $\mathrm{TiO}_{2}$ (Alfa Aesar, 99.99\%) were mixed in an appropriate molar ratio (1:3). The powder mixture was then homogenized for $24 \mathrm{~h}$ using a ball mill and pressed into pellets. Afterwards, the pellets were heated to $750{ }^{\circ} \mathrm{C}$ with $100^{\circ} \mathrm{C} / \mathrm{h}$ in a corundum crucible to expel $\mathrm{CO}_{2}$. After holding them at $750^{\circ} \mathrm{C}$ for $24 \mathrm{~h}$, the pellets were kept at $1050^{\circ} \mathrm{C}$ for $3 \mathrm{~d}$. Grinding in an agate mortar yielded $\mathrm{Li}_{2} \mathrm{Ti}_{3} \mathrm{O}_{7}$ as colorless powder.

Anal. found: $\mathrm{Li}, 5.08(7) ; \mathrm{Ti}, 53.7(4)$. Calc. for $\mathrm{Li}_{2} \mathrm{O}_{7} \mathrm{Ti}_{3}$ (269.47): Li, 5.15; Ti, 53.29wt\%.

\subsection{Neutron Diffraction}

Measurements were carried out at the fine resolution powder diffractometer (FIREPOD) [31] at the Berlin Research Reactor BER II (HZB, Germany) with Ge(511)-monochromated neutrons $(\lambda=179.82[1] \mathrm{pm})$ in Debye-Scherrer geometry. The compacted powder sample was mounted in a vacuum high-temperature furnace inside a vanadium cylinder $(d=5.95 \mathrm{~mm}, h=50.14 \mathrm{~mm})$. Measurements were carried out at $24-808^{\circ} \mathrm{C}$ with exposure times of eleven hours. Data were recorded with an array of eight "DENEX" ${ }^{3} \mathrm{He}$-counter area-detectors, yielding a final range of $0^{\circ} \leq 2 \theta \leq 142^{\circ}$ with $\Delta(2 \theta)=0.075^{\circ}$. Starting at $612^{\circ} \mathrm{C}$, the metastable specimen decomposed into the stable products $\mathrm{Li}_{4} \mathrm{Ti}_{5} \mathrm{O}_{12}$ and rutile. As in the first seven hours at that temperature no significant amounts of these phases occurred, the data acquired during this period was used for refinement. Table 1 lists further experimental details. 
Table 1. Details of neutron powder diffraction at ramsdellite-like $\mathrm{Li}_{2} \mathrm{Ti}_{3} \mathrm{O}_{7}$.

\begin{tabular}{|c|c|c|c|c|}
\hline$\vartheta /{ }^{\circ} \mathrm{C}$ & 24 & 201 & 422 & 612 \\
\hline Crystal system & orthorhombic & orthorhombic & orthorhombic & orthorhombic \\
\hline Space group & Pnma & Pnma & Pnma & Pnma \\
\hline$a / p m$ & $9.5496(3)$ & $9.5819(7)$ & $9.6101(8)$ & $9.6465(9)$ \\
\hline$b / \mathbf{p m}$ & $2.94557(9)$ & $2.9531(2)$ & $2.9605(2)$ & $2.9710(3)$ \\
\hline$c / \mathbf{p m}$ & $5.01715(13)$ & $5.0305(4)$ & $5.0450(4)$ & $5.0656(5)$ \\
\hline$V / 10^{6} \mathbf{p m}^{3}$ & $141.127(7)$ & $142.344(19)$ & $143.54(2)$ & $145.18(2)$ \\
\hline$\rho_{\text {calc }} / \mathrm{g} \mathrm{cm}^{-3}$ & 3.6245 & 3.5935 & 3.5636 & 3.5233 \\
\hline$\mu / \mathbf{m m}^{-1}$ & 0.129 & 0.128 & 0.127 & 0.125 \\
\hline $2 \boldsymbol{\theta}_{\max } /^{\circ}$ & 140.63 & 141.50 & 140.58 & 141.35 \\
\hline Data, constr., parameters & $104,6,51$ & $106,6,46$ & $106,6,46$ & $108,0,45$ \\
\hline$R_{\mathrm{F}}\left(\mathrm{obs}^{a}\right.$, all $)$ & $0.0194,0.0234$ & $0.0251,0.0295$ & $0.0323,0.0350$ & $0.0273,0.0300$ \\
\hline$R_{\mathrm{B}}\left(\mathrm{obs}^{a}\right.$, all $)$ & $0.0234,0.0241$ & $0.0329,0.0341$ & $0.0403,0.0409$ & $0.0394,0.0401$ \\
\hline$S$ (all) & 1.47 & 1.17 & 1.30 & 1.39 \\
\hline$R_{\mathrm{p}}, w R_{\mathrm{p}}{ }^{b}$ & $0.0206,0.0263$ & $0.0242,0.0304$ & $0.0227,0.0286$ & $0.0289,0.0383$ \\
\hline$w R_{\exp } b$ & 0.0179 & 0.0261 & 0.0221 & 0.0276 \\
\hline$\rho_{\min ,} \rho_{\max } / 10^{-6} \mathrm{fm} \mathrm{pm}^{-3}$ & $-0.17,0.20$ & $-0.24,0.20$ & $-0.18,0.23$ & $-0.15,0.16$ \\
\hline CSD No. & 431128 & 431129 & 431130 & 431131 \\
\hline
\end{tabular}

${ }^{a} I>3 \sigma(I) \cdot{ }^{b} w=1 /\left[\sigma^{2}(I)+(0.01 I)^{2}\right]$.

A model for the $\mathrm{Ti}_{3} \mathrm{O}_{7}{ }^{2-}$ framework was imported [17] and refined with JANA2006 [32] against net intensities analytically corrected for absorption (cylindrical sample) using the full-matrix leastsquares algorithm with fixed elements per cycle. The region $0 \leq 2 \theta \leq 20^{\circ}$ contained no reflections, but showed artifacts and was thus excluded from refinement. The background was defined manually with 26-31 points interpolated using ten Legendre polynomials with refined coefficients. Reflection profiles were fitted with a pseudo-Voigt function following the Thompson-Cox-Hastings approach [33]. Asymmetry was corrected for using the Bérar-Baldinozzi method [34] with two parameters.

First, the framework ions were refined with individual isotropic displacement parameters $U_{\text {iso. }}$ Probable lithium positions were then searched for in difference Fourier maps, yielding Li2 and Li3. Their positions and occupations were subsequently refined. For Li2, $U_{\text {iso }}$ could also be refined, whereas it had to be fixed to a value near $U_{\text {iso }}(\mathrm{Li} 2)$ for $\mathrm{Li} 3$ to warrant meaningful results. Anisotropic displacement parameters (ADPs) were introduced for the framework ions and, finally, lithium occupation at Li1 was allowed. At $24^{\circ} \mathrm{C}$, the refinement of Li2 with ADPs, even including anharmonic terms of the third order, was possible. Only statistically meaningful tensorial coefficients $\left(C_{i j k} \geq 3 \sigma\left[C_{i j k}\right]\right)$ were kept in the refinement. Note that, because of the strong disorder of the interstitial lithium ions over several lowly occupied positions, the final models appear lithium deficient with respect to the real composition. 
Analysis of the procrystal void surface under exclusion of lithium ions was performed using CRYSTALEXPlORER 3.1 [35]. For Voronoi-Dirichlet partitioning analysis, ToposPro 5.1 [36] was employed in a standard procedure: After detection, too small elementary voids (spherical-domain radius $R_{\mathrm{sd}}<136 \mathrm{pm}, 98.5 \%$ of lithium ions in oxide environments) and channels (adjacency radius $R_{\text {ad }}<180 \mathrm{pm}, 90 \%$ of typical Li-0 distance) as well as those not only determined by oxide ions (solid angle of interaction with titanium ions $\Omega>10 \% \times 4 \pi$ ) were discarded [37]. For the visualization of SLD distributions, they were reconstructed from the final structure factors put out by JANA2006 using MEM as implemented in DYSNOMIA 0.9 [38]. Starting from uniform intensities, the zeroth-order single-pixel approximation (ZSPA) [39] was employed with uncertainties adjusted by $E=0.15$ and relative weights $\lambda_{2}$ and $\lambda_{4}$ for the generalized constraints chosen to give final central moments near unity $\lambda_{n}=0$ for orders $n>4$ ). The unit cell was divided into $320 \times 96 \times 160$ voxels and set to contain the formula unit $\mathrm{Li}_{2.286} \mathrm{Ti}_{3.429} \mathrm{O}_{8}$.

Structure graphics were produced using DIAMOND 4.1 [40]. Results of calculations were visualized using VESTA 3.3 (isosurfaces) [41] and ORIGINPRo 2016 (plots) [42].

Further details of the crystal structure investigations may be obtained from FIZ Karlsruhe, 76344 Eggenstein-Leopoldshafen, Germany (fax: +49 7247 808-666; e-mail: crysdata@fiz-karlsruhe.de) on quoting the deposition numbers CSD-431128 to -431131.

\section{Results and Discussion}

\subsection{Rietveld Refinements}

Ramsdellite-like $\mathrm{Li}_{2} \mathrm{Ti}_{3} \mathrm{O}_{7}$ is said to be metastable up to about $630^{\circ} \mathrm{C}$ [11], at which point it should transform into the hexagonal polymorph that finally decomposes into $\mathrm{Li}_{4} \mathrm{Ti}_{5} \mathrm{O}_{12}$ and rutile around $800{ }^{\circ} \mathrm{C}$ [9]. Our data-collection strategy thus comprised measurements at $24,201,422,612,713$, and $808^{\circ} \mathrm{C}$ (due to slight shifts caused by the oven's temperature regulation). To our surprise, we did not detect the formation of $\mathrm{H}-\mathrm{Li}_{2} \mathrm{Ti}_{3} \mathrm{O}_{7}$ at $612{ }^{\circ} \mathrm{C}$ or above, but an immediate decomposition after maintaining this temperature for the first seven hours. As lithium transport in the main product $\mathrm{Li}_{4} \mathrm{Ti}_{5} \mathrm{O}_{12} \mathrm{had}$ already been thoroughly investigated using neutron diffraction $[16,43]$, we did not concern ourselves with the data acquired at 612 (after seven hours), 713, and $808^{\circ} \mathrm{C}$. Our finding corroborates the assumption that phase transformation and decomposition compete and the latter depends on the presence of small amounts of dopants like niobium(V) [10]. That said, we have payed special attention to effects of these reactions, which may superpose those of lithium diffusion at $612^{\circ} \mathrm{C}$.

Rietveld refinements proceeded smoothly for the $\mathrm{Ti}_{3} \mathrm{O}_{7}{ }^{2-}$ framework, but proved somewhat cumbersome when including lithium ions. Probable lithium positions (Li2 and Li3) were located on difference Fourier maps of the SLD. In addition, we allowed the occupation of the framework cation position (Li1, $c f$. Introduction). Although chemical analysis showed that the lithium content at r.t. is nominal, we decided not to constrain the occupancy sum to match it, because signs of disorder over positions not included in the model were obvious. Fig. 2 shows a typical diffractogram with its final Rietveld fit (see Figs. S1-S3 for the remaining ones); Table 2 lists atomic parameters and the sum of found lithium occupancy. 


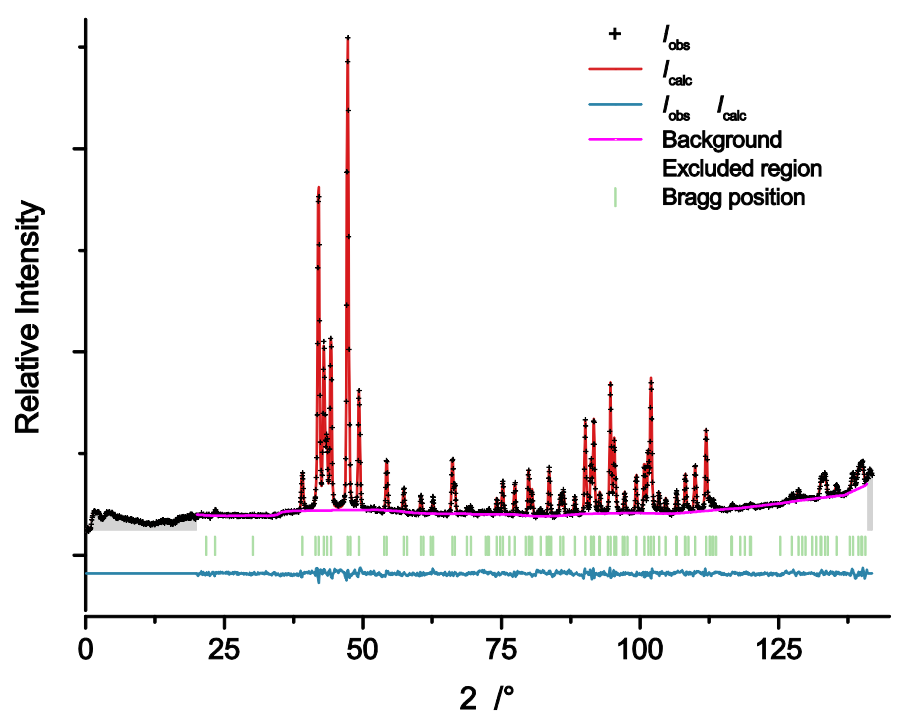

Fig. 2. Exemplary neutron diffractogram of $\mathrm{Li}_{2} \mathrm{Ti}_{3} \mathrm{O}_{7}$ at $24^{\circ} \mathrm{C}$ with results of the Rietveld refinement.

Table 2. Atomic coordinates, displacement parameters, and site occupation factors (s.o.f.) as derived from neutron diffraction.

\begin{tabular}{|c|c|c|c|c|}
\hline$\vartheta /{ }^{\circ} \mathrm{C}$ & 24 & 201 & 422 & 612 \\
\hline \multicolumn{5}{|l|}{ Ti1/Li1 (4c) } \\
\hline$x$ & $0.3587(4)$ & $0.3602(5)$ & $0.3594(5)$ & $0.3626(7)$ \\
\hline$y$ & $1 / 4$ & $1 / 4$ & $1 / 4$ & $1 / 4$ \\
\hline$z$ & $0.0287(6)$ & $0.0278(7)$ & $0.0271(7)$ & $0.0339(12)$ \\
\hline$U_{\mathrm{eq}} / 10^{4} \mathrm{pm}^{2}$ & $0.0184(10)$ & $0.0261(14)$ & $0.0270(14)$ & $0.031(2)$ \\
\hline s.o.f. (Ti1) & 0.8571 & 0.8571 & 0.8571 & 0.8571 \\
\hline s.o.f. (Li1) & $0.07(2)$ & $0.05(2)$ & $0.00(2)$ & 0 \\
\hline \multicolumn{5}{|l|}{$\mathrm{Li} 2(4 c)$} \\
\hline$x$ & $0.055(3)$ & $0.049(3)$ & $0.064(6)$ & $0.069(13)$ \\
\hline$y$ & $1 / 4$ & $1 / 4$ & $1 / 4$ & $1 / 4$ \\
\hline $\boldsymbol{Z}$ & $0.093(5)$ & $0.062(4)$ & $0.055(7)$ & $0.046(13)$ \\
\hline$U_{\text {iso }} / 1^{4} \mathbf{p m}^{2}$ & - & $0.052(12)$ & $0.07(2)$ & $0.08(3)$ \\
\hline$U_{\mathrm{eq}} / 1^{4} \mathbf{p m}^{2}$ & $0.088(14)$ & - & - & - \\
\hline s.o.f. & $0.36(4)$ & $0.29(3)$ & $0.22(4)$ & $0.23(7)$ \\
\hline \multicolumn{5}{|l|}{$\mathrm{Li} 3(4 c)$} \\
\hline$x$ & $0.450(8)$ & $0.449(6)$ & $0.464(7)$ & $0.486(13)$ \\
\hline$y$ & $1 / 4$ & $1 / 4$ & $1 / 4$ & $1 / 4$ \\
\hline$z$ & $0.434(12)$ & $0.456(8)$ & $0.457(8)$ & $0.422(13)$ \\
\hline$U_{\text {iso }} / 1^{4} \mathrm{pm}^{2}$ & 0.05 & 0.045 & 0.075 & 0.08 \\
\hline s.o.f. & $0.135(19)$ & $0.153(16)$ & $0.21(2)$ & $0.20(5)$ \\
\hline $01(4 c)$ & & & & \\
\hline
\end{tabular}




\begin{tabular}{|c|c|c|c|c|}
\hline $\boldsymbol{x}$ & $0.22626(18)$ & $0.2257(2)$ & $0.2251(2)$ & $0.2236(4)$ \\
\hline$y$ & $1 / 4$ & $1 / 4$ & $1 / 4$ & $1 / 4$ \\
\hline$z$ & $0.3280(4)$ & $0.3238(5)$ & $0.3225(5)$ & $0.3253(7)$ \\
\hline$U_{\mathrm{eq}} / 10^{4} \mathrm{pm}^{2}$ & $0.0264(7)$ & $0.0299(8)$ & $0.0336(9)$ & $0.0399(14)$ \\
\hline s.o.f. & 1 & 1 & 1 & 1 \\
\hline \multicolumn{5}{|l|}{$02(4 c)$} \\
\hline $\boldsymbol{x}$ & $0.03251(16)$ & $0.0342(2)$ & $0.0346(2)$ & $0.0348(4)$ \\
\hline$y$ & $1 / 4$ & $1 / 4$ & $1 / 4$ & $1 / 4$ \\
\hline $\mathbf{Z}$ & $0.7041(3)$ & $0.7028(4)$ & $0.7025(4)$ & $0.7027(6)$ \\
\hline$U_{\mathrm{eq}} / 10^{4} \mathrm{pm}^{2}$ & $0.0213(6)$ & $0.0250(8)$ & $0.0308(8)$ & $0.0389(14)$ \\
\hline s.o.f. & 1 & 1 & 1 & 1 \\
\hline Lithium found ${ }^{a}$ & $2.254(98.6 \%)$ & $1.944(85.0 \%)$ & $1.762(77.1 \%)$ & $1.746(76.4 \%)$ \\
\hline
\end{tabular}

aSum over the positions $\mathrm{Li} 1, \mathrm{Li} 2$, and $\mathrm{Li} 3$; relative values referring to the formula unit $\mathrm{Li}_{2.286} \mathrm{Ti}_{3.429} \mathrm{O}_{8}$ $(Z=1)$.

We found a very low occupation of the framework cation position by lithium (Li1), being significant only at $24{ }^{\circ} \mathrm{C}$ with merely one percentage point above the $3 \sigma$ level. It is safe to assume that at least a part of the disorder present at this temperature is static. We were able to recover nearly the full nominal lithium content and to refine Li2 with ADPs-even including anharmonic terms of the third order (trials to include fourth-order terms did not lead to stable refinements with physically meaningful results). These terms allow for displacement that cannot not be described by harmonic-isotropic (spherical, univariate Gaussian) or anisotropic (ellipsoidal, trivariate Gaussian)-models. The shape of resulting probability-density function (PDF) isosurfaces represents the summary displacement, in the case of neutron diffraction caused only by static or dynamic disorder of the nuclei. Although this formalism was originally developed to model the latter (i.e., thermal displacement), it may also be used to describe a static distribution with some caveats. In our case (see Fig. 3), the probability density of Li2 stretches out along the channels and towards Li3. If interpreted as a space-averaged "snapshot" of high-temperature behavior, this hints at low occupation of several energetically similar positions.

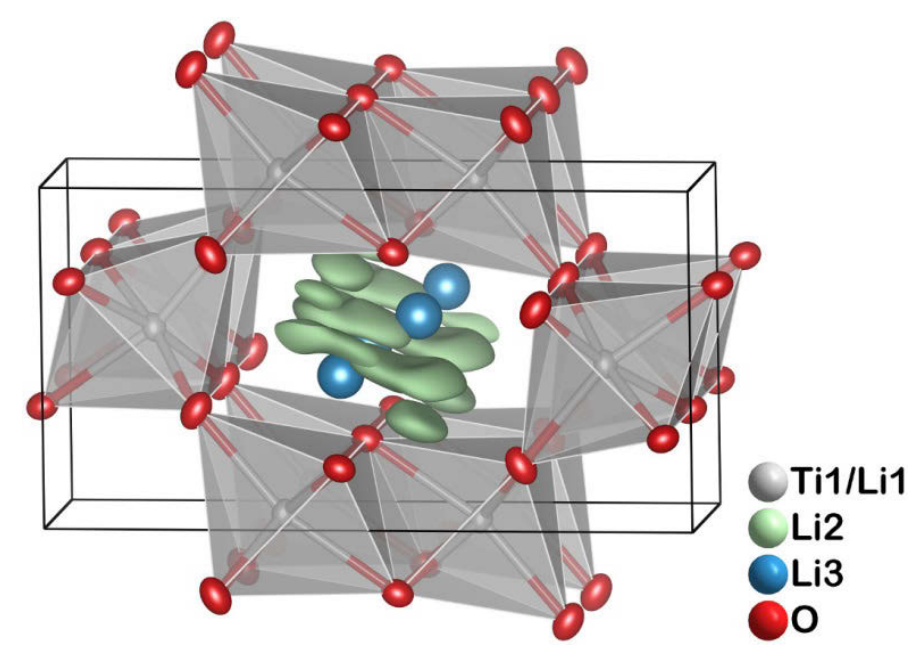

Fig. 3. Detail of the crystal structure of $\mathrm{Li}_{2} \mathrm{Ti}_{3} \mathrm{O}_{7}$ at $24{ }^{\circ} \mathrm{C}$. View approximately along $b$, Li2 as PDF isosurface of $0.1 \times 10^{-6} \mathrm{pm}^{-3}$, other ions as spheres and ellipsoids of $50 \%$ probability, unit cell in black.

The r.t. models acquired from neutron and X-ray diffraction (cf. Supporting Information, section 2) are reconcilable. It should be noted that, in the case of X-rays, the absolute values of the isotropic displacement parameters suffer from strong correlation with the roughness correction and cannot be 
compared with those derived from neutron measurements. Astonishingly, the occupation factors of lithium ions are qualitatively reproduced (high for Li2, low for Li3, very low for Li1), in spite of lithium being a notoriously weak X-ray scatterer.

Judging from the $R$ values of refinements on neutron data (see Table 1), the quality of fit decreases with rising temperature. We attribute this to dynamic disorder of the interstitial lithium ions, i.e., thermally activated lithium-ion diffusion. We have failed to adequately describe their complex distribution at $201^{\circ} \mathrm{C}$ and above with any classical model more sophisticated then isotropic displacement. This resulted in an increase of the modulus of residual SLD in the interstitial, which is furthermore far from featureless. In accordance, the reconstructed lithium content (including only the positions Li1, $\mathrm{Li} 2$, and Li3) decreases with temperature, so that above $400{ }^{\circ} \mathrm{C}$ only slightly more than $75 \%$ of the nominal value was found (evaporation of lithium oxide can be ruled out as a reason, because all measurements were conducted far below its boiling and melting point and the vanadium container was tightly sealed). Additionally, strong correlations between the isotropic displacement parameters of Li2 and Li3 occurred: if the site occupation factor (s.o.f.) of one was artificially lowered, the other one compensated for it by coordinate shifts, an increased s.o.f. and isotropic displacement.

In the refinement of the data acquired at $612{ }^{\circ} \mathrm{C}$, additional irregularities ensued. These include markedly different orientations of the displacement ellipsoids and unexpected changes in bond lengths of Ti1 and 02, as well as a change of the coordination polyhedron for Li3 from distorted tetrahedral to distorted trigonal/trigonal-bipyramidal ( $c f$. Table S2). Because of the ambiguity between fast lithium diffusion and the onset of decomposition, we consider it unsound to attribute the irregularities to either of them and refrain from discussing this dataset in inappropriate detail.

In summary, we found a nontrivial lithium ion distribution in the channels of ramsdellite-like $\mathrm{Li}_{2} \mathrm{Ti}_{3} \mathrm{O}_{7}$ at r.t. When increasing the temperature to $422^{\circ} \mathrm{C}$, thermally activated diffusion leads to a rather flat distribution that cannot be handled adequately by established models. As this hindered rigorous evaluation of activation barriers [44, 45], we were interested in finding out about the plausibility of lithium migration mechanisms already proposed for elevated temperatures.

\subsection{Topological Analyses}

Topological analyses offer such insight and provide ample more information than crystal-chemical rules of thumb. For a first assessment, we chose analysis of the procrystal void surface, which had already proven its value with potential ion conductors [45-47]. To model a channel with intact boundaries as well as one with an adjacent framework vacancy, we set up an ordered $2 \times 2 \times 2$ supercell with no lithium and nearly full titanium occupation $\left(\mathrm{Ti}_{31} \mathrm{O}_{64}{ }^{4-}\right)$. Note that the ion positions are derived from a space- and time-averaged structure, which is locally unrelaxed and does thus not represent a state of thermodynamic equilibrium.

At $422^{\circ} \mathrm{C}$, a void surface exists for procrystal densities of $\rho_{\text {pro }} \geq 0.0045$ a.u., showing isolated cusps in the tetrahedral voids of the structure. For $\rho_{\text {pro }} \geq 0.005$ a.u., these cusps connect to ribbons running along $b$. The framework defect is also visible at this isovalue, but does not connect to two/three channels below $0.0055 / 0.006$ a.u., respectively (see Fig. 4). At $24{ }^{\circ} \mathrm{C}$, the structure shows the same features for slightly higher isovalues. This is expected, because thermal contraction makes the available voids less spacious. While all these values are somewhat higher than anticipated for a rigid framework [46], they do offer some insight into this well-established ion conductor. Firstly, the broad and featuredeprived ribbons indicate that, from a purely topological point of view, many positions in the channel are available and similarly favorable. Secondly, a possible diffusion between channels would occur 
through framework vacancies (connecting two to three channels), but be disfavored compared to inchannel migration.
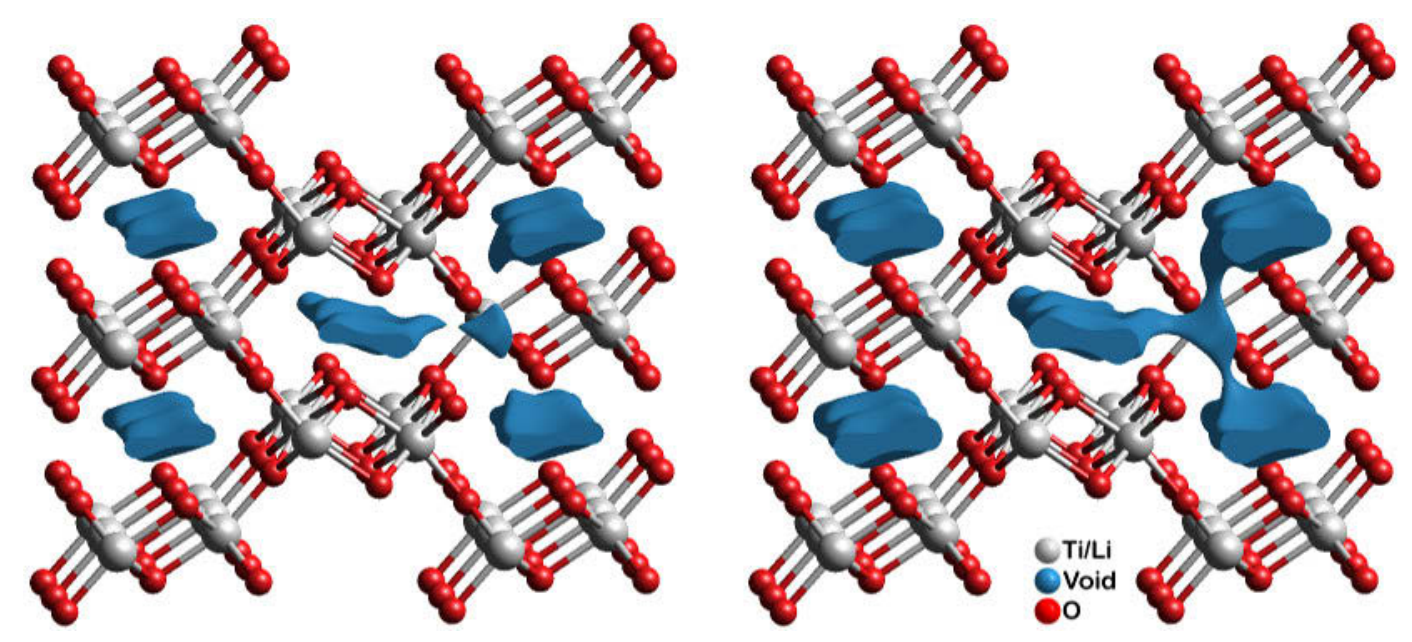

Fig. 4. Procrystal void surface of the $\mathrm{Ti}_{3} \mathrm{O}_{7}{ }^{2-}$ framework at $422^{\circ} \mathrm{C}$ for $\rho_{\text {pro }}=0.005$ a.u. (left) and $\rho_{\text {pro }}=0.006$ a.u. (right). Details showing intact channels on the left and a framework vacancy on the right, ions with arbitrary radii.

The Voronoi-Dirichlet partitioning (VDP) analysis of the framework takes into account the size of migrating ion, elementary voids and channels, as well as the crystal-chemical environment. Therefore, it offers deeper insight into the reasons for (dis-)favoring certain pathways and has already been successfully applied to fast ion conductors [37]. We used the $2 \times 2 \times 2$ supercell model introduced above $\left(422^{\circ} \mathrm{C}\right.$ ) and performed a standard procedure (see section 2.2 ) with slightly relaxed exclusion criteria (necessary spherical-domain radius: $-1.5 \%$ ).

Its consequent application leaves only three kinds of significant voids, all of them situated in the interstitial space (see Fig. 5). They form zig-zag chains along $b$, which are connected pairwise (one pair per channel) to fused six-membered rings. These constitute ribbons that are reminiscent of those found by procrystal analysis. This arrangement shows the most probable, preferred migration path for lithium ions. Interestingly, the positions $\mathrm{Li} 2$ and Li3, as derived from diffraction, are significantly displaced with respect to the nearest elementary void centers. At $24{ }^{\circ} \mathrm{C}$, in contrast, the "well-behaved" Li2 coincides with such a center. The displacement may thus be a reason or an indicator for the refinement problems experienced with classical models. As we were also interested in potential paths between interstitial channels, we included probabilistic (i.e., non-ideal or hindered) elementary voids and channels in the analysis. This left two additional possibilities for the migration of lithium ions (ideal void radius: $R_{\mathrm{sd}}=138 \mathrm{pm}$, ideal channel radius: $R_{\mathrm{ad}}=180 \mathrm{pm}$ ): one path through the center of the edge of a $\mathrm{TiO}_{6}$ octahedron (bottlenecks: $R_{\mathrm{sd}}=131 \mathrm{pm}, R_{\mathrm{ad}}=146 \mathrm{pm}$, significantly determined by cations; furthest hop distance: $r=230 \mathrm{pm})$ and one path through a framework vacancy $\left(R_{\mathrm{sd}}=124 \mathrm{pm}\right.$, $R_{\mathrm{ad}}=165 \mathrm{pm}$, determined only by anions; $r=205 \mathrm{pm}$; see Fig. 5). Even if this vacancy with its $R_{\mathrm{sd}}=124 \mathrm{pm}$ is far too small to permanently host a lithium ion, the path including it is preferred according to all other criteria. 


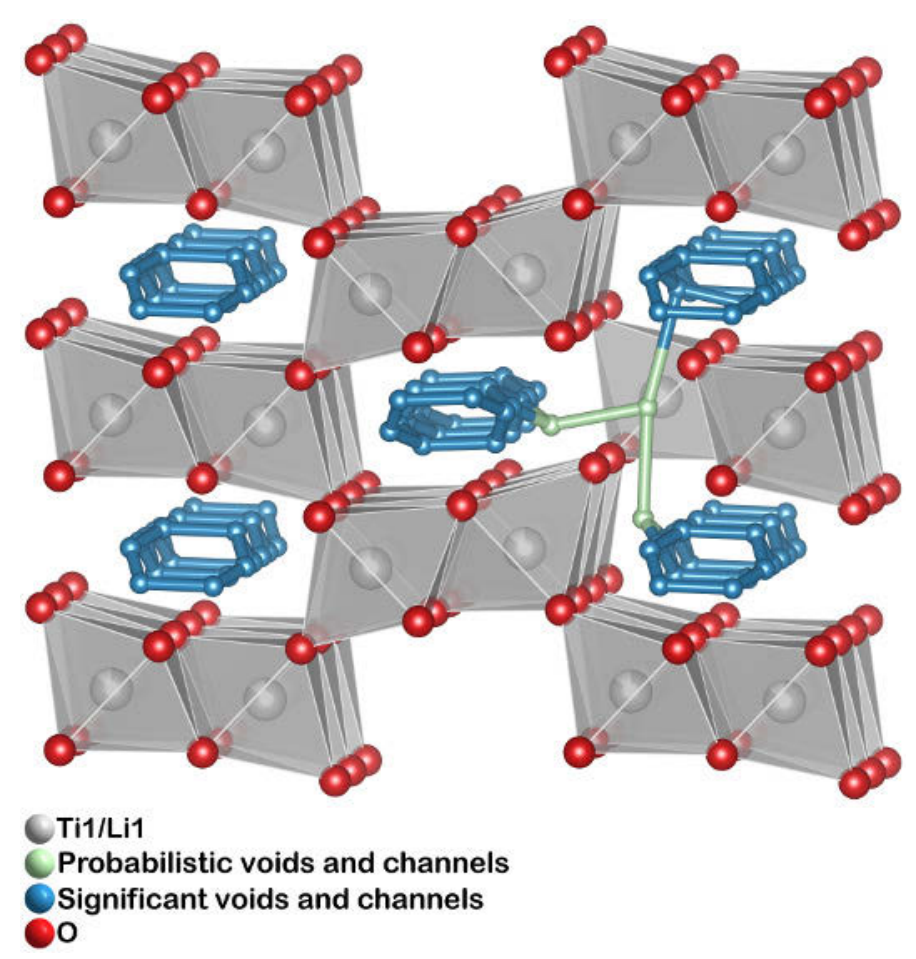

Fig. 5. Void structure of the $\mathrm{Ti}_{3} \mathrm{O}_{7}{ }^{2-}$ framework at $422^{\circ} \mathrm{C}$ as found by VDP analysis. Detail showing intact channels on the left and a framework vacancy on the right; ions, void centers, and channels with arbitrary radii.

In summary, the topological analyses corroborate a preference for diffusion in the channels along $b$. The most probable path between these channels-for reasons of size and chemical environmentincludes framework vacancies. As it is however still disfavored and framework vacancies are less frequent than interstitial vacancies, conduction along $a$ and $c$ is indeed expected to be much less efficient than along $b$.

\subsection{Scattering-Length Density Distributions}

After having evaluated the probability of suggested diffusion pathways, we wanted to check if the data acquired from diffraction experiments indeed corroborate our findings. For this purpose, we had a closer look at the SLD distribution within the unit cell. Unfortunately, traditionally constructed distributions (via Fourier synthesis from structure factors) suffer from noise and termination artifacts. To overcome this, we employed MEM, which is a versatile approach to the estimation of a model from a limited amount of information by maximizing information entropy under constraints consistent with observed physical quantities [48]. In the crystallographic case, MEM gives the maximum variance of calculated structure factors within standard deviations of observed structure factors and has already become a well-established technique in the visualization of lithium diffusion pathways $[49,50]$, even for lower-quality datasets [51].

MEM reconstruction led to physically sensible results with good fits to the data, although the one at $612{ }^{\circ} \mathrm{C}$ is of somewhat lower quality ( $c f$. Table S5). Inspection of plots for high-SLD isosurfaces showed that atomic positions are reproduced with some deviation for the interstitial lithium ions (especially Li3). Unfortunately, both of the present cations exhibit negative scattering lengths in their natural mixture (Li: $-1.90[2] \mathrm{fm}$, Ti: $-3.370[13] \mathrm{fm}$ ) [52]; and not only is titanium the stronger scatterer, but also more abundant in this compound. It is, however, safe to assume that interstitial negative SLD is only caused by lithium ions, as titanium(IV) ions are immobile. 
In isosurface plots (see Fig. 6) at $24^{\circ} \mathrm{C}$, the ribbons suggested by topological methods are discernible. At $201{ }^{\circ} \mathrm{C}$, however, they disconnect to form isolated blobs stretching along $a$. At even higher temperatures, smearing is observed until, at $612{ }^{\circ} \mathrm{C}$, small arms of SLD stretch out from the framework positions towards the channels. This suggests that the structure at r.t. is indeed a statically disordered "snapshot" of the fluctuating structure during synthesis at $1050^{\circ} \mathrm{C}$. On heating, it relaxes by depopulating energetically less favored lithium positions in the channels (disconnection). Further heat again increases thermal displacement (smearing) until framework positions may actually be involved (arms). We understand this very last point as a mere hint, as the model at $612^{\circ} \mathrm{C}$ is not of the same quality as those below this temperature (vide supra).
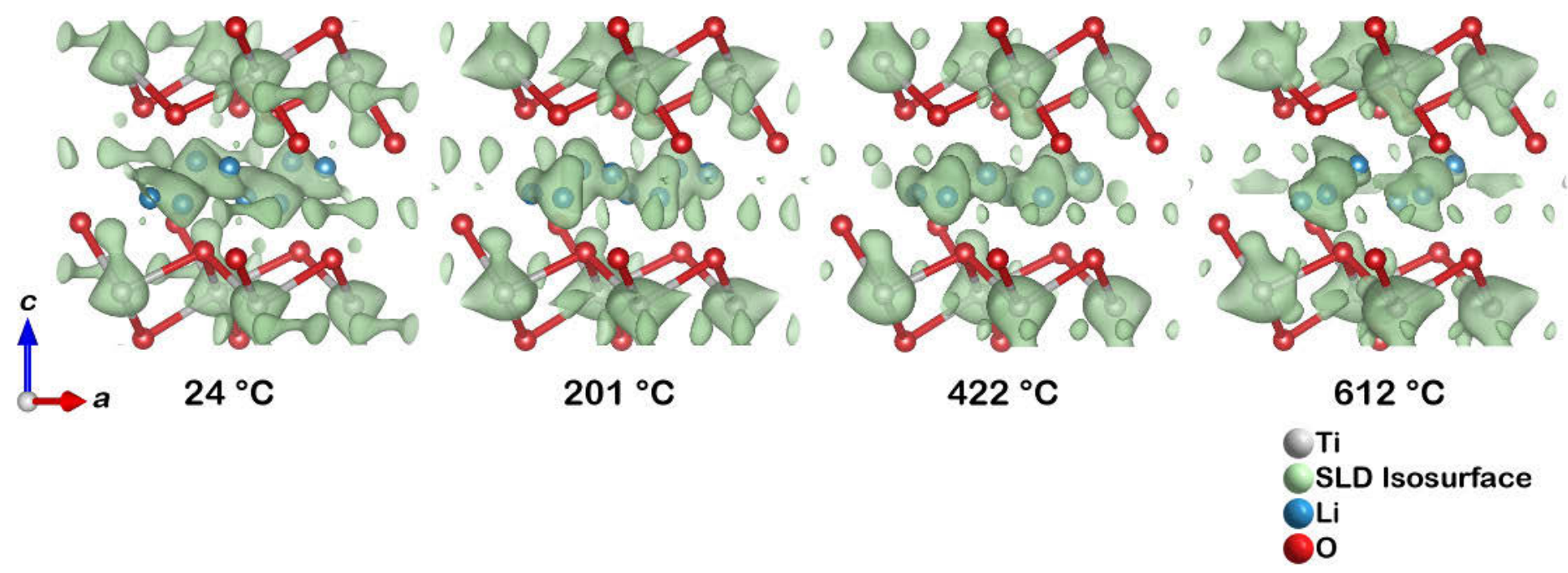

Fig. 6. Details of the crystal structure of $\mathrm{Li}_{2} \mathrm{Ti}_{3} \mathrm{O}_{7}$ at different temperatures with isosurface for scatteringlength density (SLD) of $\rho_{\mathrm{b}}=-0.08 \times 10^{-6} \mathrm{fm} \mathrm{pm}^{-3}$. View approximately along [3 $\overline{10} 0$ ], ions with arbitrary radii.

\section{Conclusions}

In line with contemporary publications, we found further evidence that lithium ions almost exclusively occupy interstitial positions in ramsdellite-like $\mathrm{Li}_{2} \mathrm{Ti}_{3} \mathrm{O}_{7}$. Any minor occupation of the framework cation position is energetically disfavored, metastable, and caused by only few ions arrested during migration at high temperature. Inside the interstitial channels, we did not observe split lithium positions, but a rather broad and flat distribution of negative SLD. This caused problems in refinement of classical discrete-atom models and may be the reason for the fit of split models to comparable datasets.

With respect to lithium occupation, the r.t. structure is most fittingly interpreted as a mostly static "snapshot" of the highly dynamic situation at the synthesis temperature of more than $950{ }^{\circ} \mathrm{C}$. Herein, numerous energetically similar positions are assumed, each with rather low occupancy. Upon heating, the lithium ions become increasingly mobile. This leads from partial relaxation at $201^{\circ} \mathrm{C}$ to additional thermally induced displacement at $422^{\circ} \mathrm{C}$, as witnessed by smearing of negative SLD. At $612{ }^{\circ} \mathrm{C}$, the border of the metastability range is reached: pure ramsdellite-like $\mathrm{Li}_{2} \mathrm{Ti}_{3} \mathrm{O}_{7}$ decomposes slowly, but immediately into spinel-like $\mathrm{Li}_{4} \mathrm{Ti}_{5} \mathrm{O}_{12}$ and rutile, without transforming to (probably dopant-stabilized) hexagonal $\mathrm{Li}_{2} \mathrm{Ti}_{3} \mathrm{O}_{7}$.

Thorough topological analyses of procrystal voids and Voronoi-Dirichlet partitioning of the $\mathrm{Ti}_{3} \mathrm{O}_{7}{ }^{2-}$ framework reveal that migration along zig-zag chains in the channels along $b$ is the strongly preferred 
mechanism for lithium diffusion. Additionally, hops between two chains adjacent in $a$ direction in the same channel are possible. Interchannel transport, on the other hand, is less favored, but may occur through an-albeit less abundant-framework cation vacancy. These findings account for the anisotropy of ionic conductivity that has been found previously: $\sigma_{b} \gg \sigma_{a}>\sigma_{c}$.

\section{Acknowledgements}

The authors would like to thank Marc R. Krey (Leibniz Universität Hannover) for performing ICPOES. We thank HZB for the allocation of neutron radiation beamtime. Financial support by the Deutsche Forschungsgemeinschaft (FOR 1277: "Mobilität von Lithiumionen in Festkörpern [molife]") is gratefully acknowledged.

\section{References}

[1] G.H. Jonker, in: Trabajos de la Tercera Reunión Internacional sobre Reactividad de los Sólidos, Consejo Superior de Investigaciones Científicas (CSIC), Madrid, 1957, pp. 413-421.

[2] M. Lundberg, S. Andersson, Acta Chem. Scand. 18 (1964) 817.

[3] B. Morosin, J.C. Mikkelsen Jr., Acta Crystallogr., Sect. B: Struct. Crystallogr. Cryst. Chem. 35 (1979) 798-800.

[4] A.M. Byström, Acta Chem. Scand. 3 (1949) 163-173.

[5] L.A.H. MacLean, F.L. Tye, Acta Chem. Scand. 49 (1995) 467-468.

[6] J. Lima-de-Faria, E. Hellner, F. Liebau, E. Makovicky, E. Parthé, Acta Crystallogr., Sect. A: Found. Crystallogr. 46 (1990) 1-11.

[7] S. Kikkawa, F. Yasuda, M. Koizumi, Mater. Res. Bull. 20 (1985) 1221-1227.

[8] K. Chiba, N. Kijima, Y. Takahashi, Y. Idemoto, J. Akimoto, Solid State Ionics 178 (2008) 17251730.

[9] J.C. Mikkelsen Jr., J. Am. Ceram. Soc. 63 (1980) 331-335.

[10] P. Bordet, C. Bougerol Chaillout, I.E. Grey, J.L. Hodeau, O. Isnard, J. Solid State Chem. 152 (2000) 546-553.

[11] D. Tsubone, M. Iwamoto, T. Shimizu, J. Ceram. Soc. Jpn. 100 (1992) 791-796.

[12] A. Orera, M.T. Azcondo, F. García-Alvarado, J. Sanz, I. Sobrados, J. Rodríguez-Carvajal, U. Amador, Inorg. Chem. 48 (2009) 7659-7666.

[13] D. Tang, C.M. Teng, J. Zou, F.H. Li, Acta Crystallogr., Sect. B: Struct. Sci. 42 (1986) 340-342.

[14] R.K.B. Gover, J.T.S. Irvine, J. Solid State Chem. 141 (1998) 365-372.

[15] L. Aldon, M. Van Thournout, P. Strobel, O. Isnard, J. Olivier-Fourcade, J.C. Jumas, Solid State Ionics 177 (2006) 1185-1191.

[16] A. Laumann, H. Boysen, M. Bremholm, K.T. Fehr, M. Hoelzel, M. Holzapfel, Chem. Mater. 23 (2011) 2753-2759. 
[17] I. Abrahams, P.G. Bruce, W.I.F. David, A.R. West, J. Solid State Chem. 78 (1989) 170-177.

[18] W. Cho, T. Kashiwagi, W. Ra, M. Nakayama, M. Wakihara, Y. Kobayashi, H. Miyashiro, Electrochim. Acta 54 (2009) 1842-1850.

[19] C.J. Chen, M. Greenblatt, Mater. Res. Bull. 20 (1985) 1347-1352.

[20] M.E. Arroyo y de Dompablo, E. Morán, A. Várez, F. García-Alvarado, Mater. Res. Bull. 32 (1997) 993-1001.

[21] M.E. Arroyo y de Dompablo, A. Várez, F. García-Alvarado, J. Solid State Chem. 153 (2000) 132139.

[22] M.M. Islam, P. Heitjans, T. Bredow, J. Phys. Chem. C 120 (2016) 5-10.

[23] J.B. Boyce, J.C. Mikkelsen Jr., Solid State Commun. 31 (1979) 741-745.

[24] S. Hayashi, H. Hatano, J. Ceram. Soc. Jpn. 102 (1994) 378-382.

[25] N. Sakai, K. Toda, M. Sato, F. Kanamaru, Key Eng. Mater. 181 (2000) 167-170.

[26] M. Umeda, K. Tuchiya, H. Kawamura, Y. Hasegawa, Y. Nanjo, Fusion Technol. 39 (2001) 654-658.

[27] P.J. Basser, C. Pierpaoli, J. Magn. Reson., Ser. B 111 (1996) 209-219.

[28] R.G. Buckley, B.P. Clayman, J.C. Mikkelsen Jr., Phys. Rev. B: Condens. Matter Mater. Phys. 26 (1982) 6509-6515.

[29] M. Van Thournout, L. Aldon, M. Womes, B. Ducourant, J. Olivier-Fourcade, C. Tessier, S. Levasseur, J. Power Sources 174 (2007) 1270-1274.

[30] F. Chen, R. Li, M. Hou, L. Liu, R. Wang, Z. Deng, Electrochim. Acta 51 (2005) 61-65.

[31] A. Franz, A. Hoser, J. Large-Scale Res. Facil. (2016), submitted.

[32] V. Petříček, M. Dušek, L. Palatinus, Z. Kristallogr. - Cryst. Mater. 229 (2014) 345-352.

[33] P. Thompson, D.E. Cox, J.B. Hastings, J. Appl. Crystallogr. 20 (1987) 79-83.

[34] J.-F. Bérar, G. Baldinozzi, J. Appl. Crystallogr. 26 (1993) 128-129.

[35] S.K. Wolff, D.J. Grimwood, J.J. McKinnon, M.J. Turner, D. Jayatilaka, M.A. Spackman, CrystalExplorer 3.1 - Crystal Structure Analysis with Hirshfeld Surfaces, University of Western Australia, Perth (Australia), 2012.

[36] V.A. Blatov, A.P. Shevchenko, D.M. Proserpio, Cryst. Growth Des. 14 (2014) 3576-3586.

[37] V.A. Blatov, G.D. Ilyushin, O.A. Blatova, N.A. Anurova, A.K. Ivanov-Schits, L.N. Dem'yanets, Acta Crystallogr., Sect. B: Struct. Sci. 62 (2006) 1010-1018.

[38] K. Momma, T. Ikeda, A.A. Belik, F. Izumi, Powder Diffr. 28 (2013) 184-193.

[39] F. Izumi, K. Momma, IOP Conf. Ser.: Mater. Sci. Eng. 18 (2011) 022001.

[40] K. Brandenburg, Diamond 4.1 - Crystal and Molecular Structure Visualization, Crystal Impact - H. Putz \& K. Brandenburg GbR, Bonn (Germany), 2015.

[41] K. Momma, F. Izumi, J. Appl. Crystallogr. 44 (2011) 1272-1276. 
[42] OriginLab, OriginPro 2016 - Data Analysis and Graphing Software, OriginLab Corp., Northampton (USA), 2016.

[43] W.K. Pang, V.K. Peterson, N. Sharma, J.-J. Shiu, S.-h. Wu, Chem. Mater. 26 (2014) 2318-2326.

[44] D. Wiedemann, M.M. Islam, S. Nakhal, A. Senyshyn, T. Bredow, M. Lerch, J. Phys. Chem. C 119 (2015) 11370-11381.

[45] D. Wiedemann, S. Nakhal, J. Rahn, E. Witt, M.M. Islam, S. Zander, P. Heitjans, H. Schmidt, T. Bredow, M. Wilkening, M. Lerch, Chem. Mater. 28 (2016) 915-924.

[46] M.Ø. Filsø, M.J. Turner, G.V. Gibbs, S. Adams, M.A. Spackman, B.B. Iversen, Chem. Eur. J. 19 (2013) 15535-15544.

[47] S. Nakhal, D. Wiedemann, B. Stanje, O. Dolotko, M. Wilkening, M. Lerch, J. Solid State Chem. 238 (2016) 60-67.

[48] F. Izumi, Solid State Ionics 172 (2004) 1-6.

[49] A. Senyshyn, H. Boysen, R. Niewa, J. Banys, M. Kinka, Y. Burak, V. Adamiv, F. Izumi, I. Chumak, H. Fuess, J. Phys. D: Appl. Phys. 45 (2012) 175305.

[50] M. Yashima, J. Ceram. Soc. Jpn. 117 (2009) 1055-1059.

[51] D. Wiedemann, S. Indris, M. Meven, B. Pedersen, H. Boysen, R. Uecker, P. Heitjans, M. Lerch, Z. Kristallogr. - Cryst. Mater. 231 (2016) 189-193.

[52] V.F. Sears, in: E. Prince (Ed.) International Tables for Crystallography, 3rd ed., Kluwer Academic Publishers, Dordrecht (Netherlands), 2004, pp. 444-454. 
structure determination). The relation of the $\mathrm{Li}_{2} \mathrm{Ti}_{3} \mathrm{O}_{7}$ structure with the $\mathrm{Li}_{0.5} \mathrm{TiO}_{2}$ type, often being assigned to it, is rather one of homeotypism by defects than of real isotypism.

Nonetheless, any of these terms is used to distinguish the common polymorph from two others: a layered one $\left(P 2_{1} / m, \mathrm{Li}_{2} \mathrm{Ti}_{3} \mathrm{O}_{7}\right.$ type, isopointal to $\mathrm{Na}_{2} \mathrm{Ti}_{3} \mathrm{O}_{7}$ type), which was first prepared in 1985 [7] and described in detail in 2008 [8], and a hexagonal one (also called $\mathrm{H}-\mathrm{Li}_{2} \mathrm{Ti}_{3} \mathrm{O}_{7}, R 3 c$ ), which was first observed in 1980 [9] and structurally elucidated in 2000 [10]. The pseudo-binary system $\mathrm{Li}_{2} \mathrm{O}-\mathrm{TiO}_{2}$ containing titanium(IV) compounds only is governed by stable phases of the compositions $\mathrm{Li}_{4} \mathrm{TiO}_{4}$, $\mathrm{Li}_{2} \mathrm{TiO}_{3}, \mathrm{Li}_{4} \mathrm{Ti}_{5} \mathrm{O}_{12}$, and $\mathrm{Li}_{2} \mathrm{Ti}_{3} \mathrm{O}_{7}$. Ramsdellite-like $\mathrm{Li}_{2} \mathrm{Ti}_{3} \mathrm{O}_{7}$ is thermodynamically stable from 950 to $1300{ }^{\circ} \mathrm{C}$ and melts above. By quenching, it can be sustained in a metastable state below this interval. Upon heating from room temperature (r.t.), it is said to transform into the hexagonal polymorph around $630{ }^{\circ} \mathrm{C}$ [11], which decomposes into spinel-like $\mathrm{Li}_{4} \mathrm{Ti}_{5} \mathrm{O}_{12}$ and $\mathrm{TiO}_{2}$ at $c a .800{ }^{\circ} \mathrm{C}$ [9].

All of the following considerations refer to ramsdellite-like $\mathrm{Li}_{2} \mathrm{Ti}_{3} \mathrm{O}_{7}$ in its standard Pnma setting. $\mathrm{Li}_{2} \mathrm{Ti}_{3} \mathrm{O}_{7}$ (or, with $Z=1, \mathrm{Li}_{2.286} \mathrm{Ti}_{3.429} \mathrm{O}_{8}$ ) can formally be divided into a framework, adopting a cation defective or site-ordering variant of the $\mathrm{VO}_{2}$ type, and interstitial lithium ions. Although the distribution of lithium ions between framework and interstitials has been assessed differently in the past, there seems to be good reason to formulate $\left[\mathrm{Li}_{2} \square_{5}\right]_{\mathrm{i}}\left[\left(\mathrm{Ti}_{3} \square_{0.5}\right) \mathrm{O}_{7}\right]_{\mathrm{f}}$ (口: vacancy, i: interstitial, f: framework) rather than $\left[\mathrm{Li}_{1.5} \square_{5.5}\right]_{\mathrm{i}}\left[\left(\mathrm{Li}_{0.5} \mathrm{Ti}_{3}\right) \mathrm{O}_{7}\right]_{\mathrm{f}}[12,13]$. The framework consists of $M \mathrm{O}_{6}$ octahedra $(M=\mathrm{Ti}$, $\mathrm{Li}, \mathrm{\square}$ ) sharing edges to form infinite chains along $b$. Again by edge-sharing, these chains are organized in pairs, which connect to the adjacent ones via common vertices. This leaves spacious channels along $b$ hosting the interstitial lithium ions (see Fig. 1). Available neutron-diffraction studies differ in the assignment of their positions: two tetrahedrally coordinated $4 c$ sites are discussed [14-16] and one of them may split in two $8 d$ sites [17]. Taking all of these positions and those in the framework into account, lithiation of $\mathrm{Li}_{2} \mathrm{Ti}_{3} \mathrm{O}_{7}$ may lead to a theoretical maximum of two additional ions per formula unit (i.e., 2.286 ions per unit cell) under reduction of titanium(IV) to titanium(III) [18]. Chemically, 0.5/1.0 ions per formula unit can be intercalated at r.t. $/ 50^{\circ} \mathrm{C}$, respectively [19]. Electrochemical lithiation, however, can add two ions under conservation of the ramsdellite-like structure. A maximum of $c a$. 2.24 intercalated ions per formula unit is possible, but accompanied by a phase transformation [20, 21].
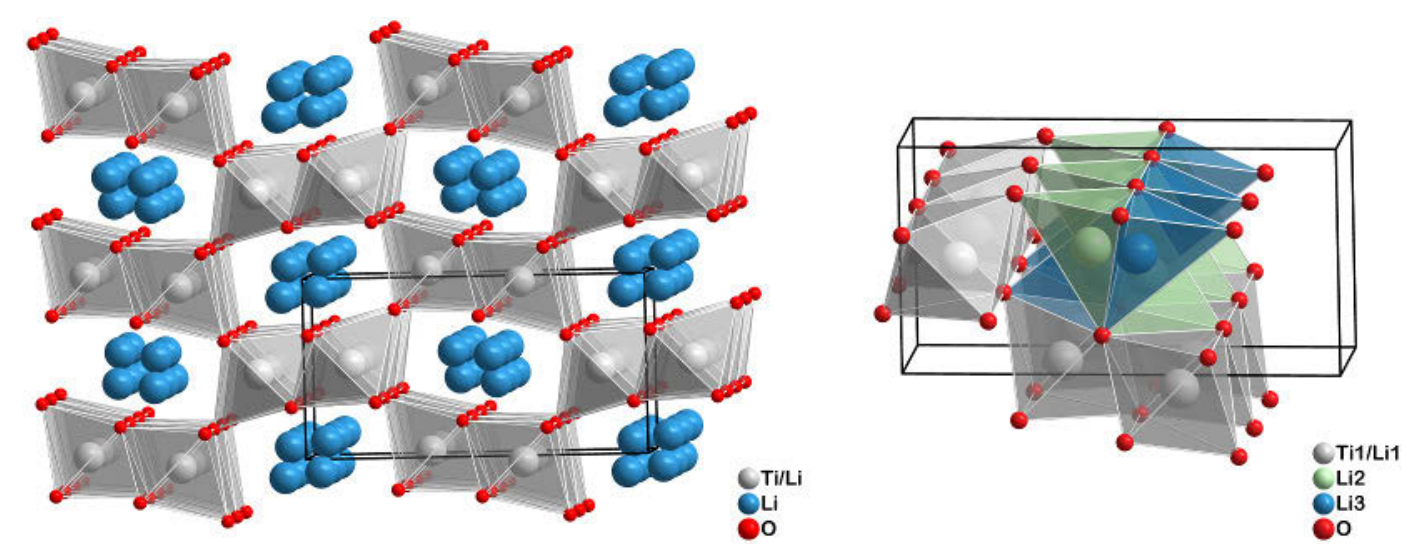

Fig. 1. Crystal structure of ramsdellite-like $\mathrm{Li}_{2} \mathrm{Ti}_{3} \mathrm{O}_{7}$ in general view (left) and channel detail (right). View approximately along $b$, ions with arbitrary radii, unit cell in black.

A most recent computational study states that " $\mathrm{Li}_{2} \mathrm{Ti}_{3} \mathrm{O}_{7}$ appears to be a (quasi) one-dimensional Liion conductor" [22] and there is indeed ample evidence to consider it preferentially one-dimensional. Early conductivity and impedance measurements on oriented single-crystals have yielded the prefactor tensor $\boldsymbol{\sigma}_{0}$ of ionic conductivity [23]: 


$$
\sigma_{0}=10^{3} \Omega^{-1} \mathrm{~cm}^{-1} \mathrm{~K} \cdot\left(\begin{array}{ccc}
29.2 & 0 & 0 \\
0 & 194.4 & 0 \\
0 & 0 & 7.7
\end{array}\right)
$$

The activation energies $E_{\mathrm{a}}$ for ion conduction in the principal crystallographic directions scatter only slightly between 0.44 and $0.47 \mathrm{eV}(0.41-0.50 \mathrm{eV}$, according to later studies [24-26]). This implies a high fractional anisotropy (FA) of $c a$. 0.90 - a quantity that can adopt values between 0 for the isotropic and 1 for the strictly one-dimensional case [27]. Probability considerations [23] and vibrational spectroscopy [28] hint at hops from an interstitial lithium site to an empty adjacent one in the channel or the framework as conduction mechanism along $b$ or $a$, respectively. However, the associated diffusion pathways have not yet been mapped or studied in depth. This fact is especially surprising, as they play a major role in most of the proposed applications, ranging from electrode material for batteries $[15,29]$ and supercapacitors [30] to matrix for lithium-isotope separation [26] and recovery of lithium from scrap alloys [10].

In this study, we present the results of neutron powder diffraction on ramsdellite-like $\mathrm{Li}_{2} \mathrm{Ti}_{3} \mathrm{O}_{7}$ at ambient and high temperatures. We settle the question of framework occupation by lithium ions, derive the most probable pathways for their diffusion, and explain the observed anisotropy of conductivity using a mixed approach: topological analyses and mapping of the scattering-length density (SLD) reconstructed using maximum-entropy methods (MEM).

\section{Experimental}

\subsection{Synthesis}

$\mathrm{Li}_{2} \mathrm{Ti}_{3} \mathrm{O}_{7}$ was prepared by solid-state synthesis according to a modified literature procedure [19]. $\mathrm{Li}_{2} \mathrm{CO}_{3}$ (Aldrich, 99.997\%) and $\mathrm{TiO}_{2}$ (Alfa Aesar, 99.99\%) were mixed in an appropriate molar ratio (1:3). The powder mixture was then homogenized for $24 \mathrm{~h}$ using a ball mill and pressed into pellets. Afterwards, the pellets were heated to $750{ }^{\circ} \mathrm{C}$ with $100^{\circ} \mathrm{C} / \mathrm{h}$ in a corundum crucible to expel $\mathrm{CO}_{2}$. After holding them at $750^{\circ} \mathrm{C}$ for $24 \mathrm{~h}$, the pellets were kept at $1050^{\circ} \mathrm{C}$ for $3 \mathrm{~d}$. Grinding in an agate mortar yielded $\mathrm{Li}_{2} \mathrm{Ti}_{3} \mathrm{O}_{7}$ as colorless powder.

Anal. found: $\mathrm{Li}, 5.08(7) ; \mathrm{Ti}, 53.7(4)$. Calc. for $\mathrm{Li}_{2} \mathrm{O}_{7} \mathrm{Ti}_{3}$ (269.47): Li, 5.15; Ti, 53.29wt\%.

\subsection{Neutron Diffraction}

Measurements were carried out at the fine resolution powder diffractometer (FIREPOD) [31] at the Berlin Research Reactor BER II (HZB, Germany) with Ge(511)-monochromated neutrons $(\lambda=179.82[1] \mathrm{pm})$ in Debye-Scherrer geometry. The compacted powder sample was mounted in a vacuum high-temperature furnace inside a vanadium cylinder $(d=5.95 \mathrm{~mm}, h=50.14 \mathrm{~mm})$. Measurements were carried out at $24-808^{\circ} \mathrm{C}$ with exposure times of eleven hours. Data were recorded with an array of eight "DENEX" ${ }^{3} \mathrm{He}$-counter area-detectors, yielding a final range of $0^{\circ} \leq 2 \theta \leq 142^{\circ}$ with $\Delta(2 \theta)=0.075^{\circ}$. Starting at $612^{\circ} \mathrm{C}$, the metastable specimen decomposed into the stable products $\mathrm{Li}_{4} \mathrm{Ti}_{5} \mathrm{O}_{12}$ and rutile. As in the first seven hours at that temperature no significant amounts of these phases occurred, the data acquired during this period was used for refinement. Table 1 lists further experimental details. 
Table 1. Details of neutron powder diffraction at ramsdellite-like $\mathrm{Li}_{2} \mathrm{Ti}_{3} \mathrm{O}_{7}$.

\begin{tabular}{|c|c|c|c|c|}
\hline$\vartheta /{ }^{\circ} \mathrm{C}$ & 24 & 201 & 422 & 612 \\
\hline Crystal system & orthorhombic & orthorhombic & orthorhombic & orthorhombic \\
\hline Space group & Pnma & Pnma & Pnma & Pnma \\
\hline$a / p m$ & $9.5496(3)$ & $9.5819(7)$ & $9.6101(8)$ & $9.6465(9)$ \\
\hline$b / \mathbf{p m}$ & $2.94557(9)$ & $2.9531(2)$ & $2.9605(2)$ & $2.9710(3)$ \\
\hline$c / \mathbf{p m}$ & $5.01715(13)$ & $5.0305(4)$ & $5.0450(4)$ & $5.0656(5)$ \\
\hline$V / 10^{6} \mathbf{p m}^{3}$ & $141.127(7)$ & $142.344(19)$ & $143.54(2)$ & $145.18(2)$ \\
\hline$\rho_{\text {calc }} / \mathrm{g} \mathrm{cm}^{-3}$ & 3.6245 & 3.5935 & 3.5636 & 3.5233 \\
\hline$\mu / \mathbf{m m}^{-1}$ & 0.129 & 0.128 & 0.127 & 0.125 \\
\hline $2 \boldsymbol{\theta}_{\max } /^{\circ}$ & 140.63 & 141.50 & 140.58 & 141.35 \\
\hline Data, constr., parameters & $104,6,51$ & $106,6,46$ & $106,6,46$ & $108,0,45$ \\
\hline$R_{\mathrm{F}}\left(\mathrm{obs}^{a}\right.$, all $)$ & $0.0194,0.0234$ & $0.0251,0.0295$ & $0.0323,0.0350$ & $0.0273,0.0300$ \\
\hline$R_{\mathrm{B}}\left(\mathrm{obs}^{a}\right.$, all $)$ & $0.0234,0.0241$ & $0.0329,0.0341$ & $0.0403,0.0409$ & $0.0394,0.0401$ \\
\hline$S$ (all) & 1.47 & 1.17 & 1.30 & 1.39 \\
\hline$R_{\mathrm{p}}, w R_{\mathrm{p}}{ }^{b}$ & $0.0206,0.0263$ & $0.0242,0.0304$ & $0.0227,0.0286$ & $0.0289,0.0383$ \\
\hline$w R_{\exp }^{b}$ & 0.0179 & 0.0261 & 0.0221 & 0.0276 \\
\hline$\rho_{\min ,} \rho_{\max } / 10^{-6} \mathrm{fm} \mathrm{pm}^{-3}$ & $-0.17,0.20$ & $-0.24,0.20$ & $-0.18,0.23$ & $-0.15,0.16$ \\
\hline CSD No. & 431128 & 431129 & 431130 & 431131 \\
\hline
\end{tabular}

${ }^{a} I>3 \sigma(I) \cdot{ }^{b} W=1 /\left[\sigma^{2}(I)+(0.01 I)^{2}\right]$.

A model for the $\mathrm{Ti}_{3} \mathrm{O}_{7}{ }^{2-}$ framework was imported [17] and refined with JANA2006 [32] against net intensities analytically corrected for absorption (cylindrical sample) using the full-matrix leastsquares algorithm with fixed elements per cycle. The region $0 \leq 2 \theta \leq 20^{\circ}$ contained no reflections, but showed artifacts and was thus excluded from refinement. The background was defined manually with 26-31 points interpolated using ten Legendre polynomials with refined coefficients. Reflection profiles were fitted with a pseudo-Voigt function following the Thompson-Cox-Hastings approach [33]. Asymmetry was corrected for using the Bérar-Baldinozzi method [34] with two parameters.

First, the framework ions were refined with individual isotropic displacement parameters $U_{\text {iso. }}$ Probable lithium positions were then searched for in difference Fourier maps, yielding Li2 and Li3. Their positions and occupations were subsequently refined. For Li2, $U_{\text {iso }}$ could also be refined, whereas it had to be fixed to a value near $U_{\text {iso }}(\mathrm{Li} 2)$ for $\mathrm{Li} 3$ to warrant meaningful results. Anisotropic displacement parameters (ADPs) were introduced for the framework ions and, finally, lithium occupation at Li1 was allowed. At $24^{\circ} \mathrm{C}$, the refinement of Li2 with ADPs, even including anharmonic terms of the third order, was possible. Only statistically meaningful tensorial coefficients $\left(C_{i j k} \geq 3 \sigma\left[C_{i j k}\right]\right)$ were kept in the refinement. Note that, because of the strong disorder of the interstitial lithium ions over several lowly occupied positions, the final models appear lithium deficient with respect to the real composition. 
Analysis of the procrystal void surface under exclusion of lithium ions was performed using CRYSTALEXPlORER 3.1 [35]. For Voronoi-Dirichlet partitioning analysis, ToposPro 5.1 [36] was employed in a standard procedure: After detection, too small elementary voids (spherical-domain radius $R_{\mathrm{sd}}<136 \mathrm{pm}, 98.5 \%$ of lithium ions in oxide environments) and channels (adjacency radius $R_{\text {ad }}<180 \mathrm{pm}, 90 \%$ of typical Li-0 distance) as well as those not only determined by oxide ions (solid angle of interaction with titanium ions $\Omega>10 \% \times 4 \pi$ ) were discarded [37]. For the visualization of SLD distributions, they were reconstructed from the final structure factors put out by JANA2006 using MEM as implemented in DYSNOMIA 0.9 [38]. Starting from uniform intensities, the zeroth-order single-pixel approximation (ZSPA) [39] was employed with uncertainties adjusted by $E=0.15$ and relative weights $\lambda_{2}$ and $\lambda_{4}$ for the generalized constraints chosen to give final central moments near unity $\lambda_{n}=0$ for orders $n>4$ ). The unit cell was divided into $320 \times 96 \times 160$ voxels and set to contain the formula unit $\mathrm{Li}_{2.286} \mathrm{Ti}_{3.429} \mathrm{O}_{8}$.

Structure graphics were produced using DIAMOND 4.1 [40]. Results of calculations were visualized using VESTA 3.3 (isosurfaces) [41] and ORIGINPRo 2016 (plots) [42].

Further details of the crystal structure investigations may be obtained from FIZ Karlsruhe, 76344 Eggenstein-Leopoldshafen, Germany (fax: +49 7247 808-666; e-mail: crysdata@fiz-karlsruhe.de) on quoting the deposition numbers CSD-431128 to -431131.

\section{Results and Discussion}

\subsection{Rietveld Refinements}

Ramsdellite-like $\mathrm{Li}_{2} \mathrm{Ti}_{3} \mathrm{O}_{7}$ is said to be metastable up to about $630^{\circ} \mathrm{C}$ [11], at which point it should transform into the hexagonal polymorph that finally decomposes into $\mathrm{Li}_{4} \mathrm{Ti}_{5} \mathrm{O}_{12}$ and rutile around $800{ }^{\circ} \mathrm{C}$ [9]. Our data-collection strategy thus comprised measurements at $24,201,422,612,713$, and $808^{\circ} \mathrm{C}$ (due to slight shifts caused by the oven's temperature regulation). To our surprise, we did not detect the formation of $\mathrm{H}-\mathrm{Li}_{2} \mathrm{Ti}_{3} \mathrm{O}_{7}$ at $612{ }^{\circ} \mathrm{C}$ or above, but an immediate decomposition after maintaining this temperature for the first seven hours. As lithium transport in the main product $\mathrm{Li}_{4} \mathrm{Ti}_{5} \mathrm{O}_{12} \mathrm{had}$ already been thoroughly investigated using neutron diffraction $[16,43]$, we did not concern ourselves with the data acquired at 612 (after seven hours), 713, and $808^{\circ} \mathrm{C}$. Our finding corroborates the assumption that phase transformation and decomposition compete and the latter depends on the presence of small amounts of dopants like niobium(V) [10]. That said, we have payed special attention to effects of these reactions, which may superpose those of lithium diffusion at $612^{\circ} \mathrm{C}$.

Rietveld refinements proceeded smoothly for the $\mathrm{Ti}_{3} \mathrm{O}_{7}{ }^{2-}$ framework, but proved somewhat cumbersome when including lithium ions. Probable lithium positions (Li2 and Li3) were located on difference Fourier maps of the SLD. In addition, we allowed the occupation of the framework cation position (Li1, $c f$. Introduction). Although chemical analysis showed that the lithium content at r.t. is nominal, we decided not to constrain the occupancy sum to match it, because signs of disorder over positions not included in the model were obvious. Fig. 2 shows a typical diffractogram with its final Rietveld fit (see Figs. S1-S3 for the remaining ones); Table 2 lists atomic parameters and the sum of found lithium occupancy. 


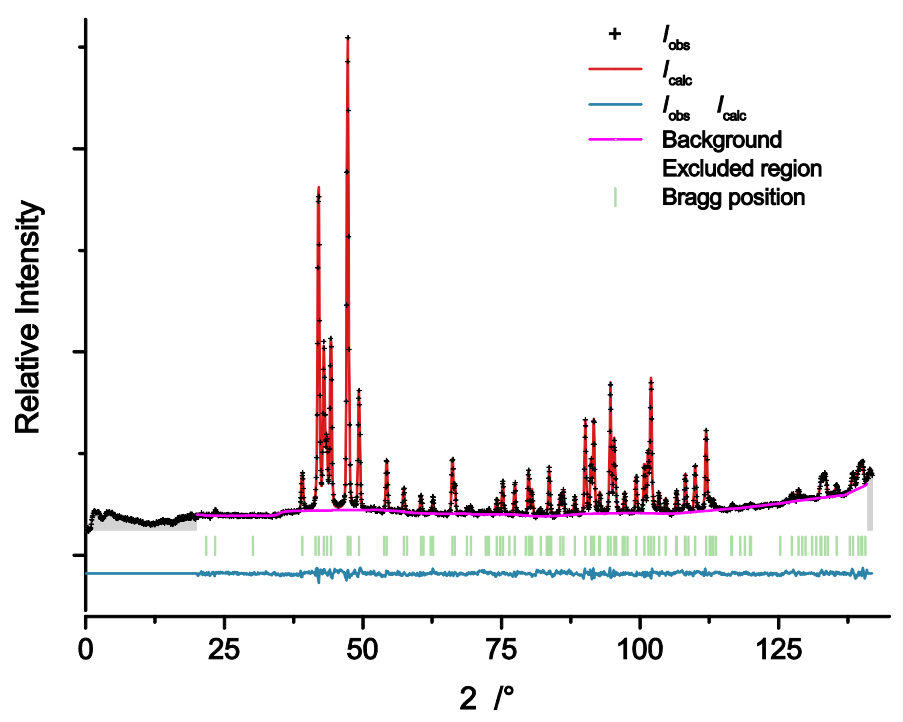

Fig. 2. Exemplary neutron diffractogram of $\mathrm{Li}_{2} \mathrm{Ti}_{3} \mathrm{O}_{7}$ at $24{ }^{\circ} \mathrm{C}$ with results of the Rietveld refinement.

Table 2. Atomic coordinates, displacement parameters, and site occupation factors (s.o.f.) as derived from neutron diffraction.

\begin{tabular}{|c|c|c|c|c|}
\hline$\vartheta /{ }^{\circ} \mathrm{C}$ & 24 & 201 & 422 & 612 \\
\hline \multicolumn{5}{|l|}{ Ti1/Li1 (4c) } \\
\hline$x$ & $0.3587(4)$ & $0.3602(5)$ & $0.3594(5)$ & $0.3626(7)$ \\
\hline$y$ & $1 / 4$ & $1 / 4$ & $1 / 4$ & $1 / 4$ \\
\hline$z$ & $0.0287(6)$ & $0.0278(7)$ & $0.0271(7)$ & $0.0339(12)$ \\
\hline$U_{\mathrm{eq}} / 10^{4} \mathrm{pm}^{2}$ & $0.0184(10)$ & $0.0261(14)$ & $0.0270(14)$ & $0.031(2)$ \\
\hline s.o.f. (Ti1) & 0.8571 & 0.8571 & 0.8571 & 0.8571 \\
\hline s.o.f. (Li1) & $0.07(2)$ & $0.05(2)$ & $0.00(2)$ & 0 \\
\hline \multicolumn{5}{|l|}{$\mathrm{Li} 2(4 c)$} \\
\hline$x$ & $0.055(3)$ & $0.049(3)$ & $0.064(6)$ & $0.069(13)$ \\
\hline$y$ & $1 / 4$ & $1 / 4$ & $1 / 4$ & $1 / 4$ \\
\hline $\boldsymbol{Z}$ & $0.093(5)$ & $0.062(4)$ & $0.055(7)$ & $0.046(13)$ \\
\hline$U_{\text {iso }} / 1^{4} \mathbf{p m}^{2}$ & - & $0.052(12)$ & $0.07(2)$ & $0.08(3)$ \\
\hline$U_{\mathrm{eq}} / 1^{4} \mathbf{p m}^{2}$ & $0.088(14)$ & - & - & - \\
\hline s.o.f. & $0.36(4)$ & $0.29(3)$ & $0.22(4)$ & $0.23(7)$ \\
\hline \multicolumn{5}{|l|}{$\mathrm{Li} 3(4 c)$} \\
\hline$x$ & $0.450(8)$ & $0.449(6)$ & $0.464(7)$ & $0.486(13)$ \\
\hline$y$ & $1 / 4$ & $1 / 4$ & $1 / 4$ & $1 / 4$ \\
\hline$z$ & $0.434(12)$ & $0.456(8)$ & $0.457(8)$ & $0.422(13)$ \\
\hline$U_{\text {iso }} / 1^{4} \mathrm{pm}^{2}$ & 0.05 & 0.045 & 0.075 & 0.08 \\
\hline s.o.f. & $0.135(19)$ & $0.153(16)$ & $0.21(2)$ & $0.20(5)$ \\
\hline $01(4 c)$ & & & & \\
\hline
\end{tabular}




\begin{tabular}{|c|c|c|c|c|}
\hline $\boldsymbol{x}$ & $0.22626(18)$ & $0.2257(2)$ & $0.2251(2)$ & $0.2236(4)$ \\
\hline$y$ & $1 / 4$ & $1 / 4$ & $1 / 4$ & $1 / 4$ \\
\hline$z$ & $0.3280(4)$ & $0.3238(5)$ & $0.3225(5)$ & $0.3253(7)$ \\
\hline$U_{\mathrm{eq}} / 10^{4} \mathrm{pm}^{2}$ & $0.0264(7)$ & $0.0299(8)$ & $0.0336(9)$ & $0.0399(14)$ \\
\hline s.o.f. & 1 & 1 & 1 & 1 \\
\hline \multicolumn{5}{|l|}{$02(4 c)$} \\
\hline $\boldsymbol{x}$ & $0.03251(16)$ & $0.0342(2)$ & $0.0346(2)$ & $0.0348(4)$ \\
\hline$y$ & $1 / 4$ & $1 / 4$ & $1 / 4$ & $1 / 4$ \\
\hline $\mathbf{Z}$ & $0.7041(3)$ & $0.7028(4)$ & $0.7025(4)$ & $0.7027(6)$ \\
\hline$U_{\mathrm{eq}} / 10^{4} \mathrm{pm}^{2}$ & $0.0213(6)$ & $0.0250(8)$ & $0.0308(8)$ & $0.0389(14)$ \\
\hline s.o.f. & 1 & 1 & 1 & 1 \\
\hline Lithium found ${ }^{a}$ & $2.254(98.6 \%)$ & $1.944(85.0 \%)$ & $1.762(77.1 \%)$ & $1.746(76.4 \%)$ \\
\hline
\end{tabular}

aSum over the positions $\mathrm{Li} 1, \mathrm{Li} 2$, and $\mathrm{Li} 3$; relative values referring to the formula unit $\mathrm{Li}_{2.286} \mathrm{Ti}_{3.429} \mathrm{O}_{8}$ $(Z=1)$.

We found a very low occupation of the framework cation position by lithium (Li1), being significant only at $24{ }^{\circ} \mathrm{C}$ with merely one percentage point above the $3 \sigma$ level. It is safe to assume that at least a part of the disorder present at this temperature is static. We were able to recover nearly the full nominal lithium content and to refine Li2 with ADPs-even including anharmonic terms of the third order (trials to include fourth-order terms did not lead to stable refinements with physically meaningful results). These terms allow for displacement that cannot not be described by harmonic-isotropic (spherical, univariate Gaussian) or anisotropic (ellipsoidal, trivariate Gaussian)-models. The shape of resulting probability-density function (PDF) isosurfaces represents the summary displacement, in the case of neutron diffraction caused only by static or dynamic disorder of the nuclei. Although this formalism was originally developed to model the latter (i.e., thermal displacement), it may also be used to describe a static distribution with some caveats. In our case (see Fig. 3), the probability density of Li2 stretches out along the channels and towards Li3. If interpreted as a space-averaged "snapshot" of high-temperature behavior, this hints at low occupation of several energetically similar positions.

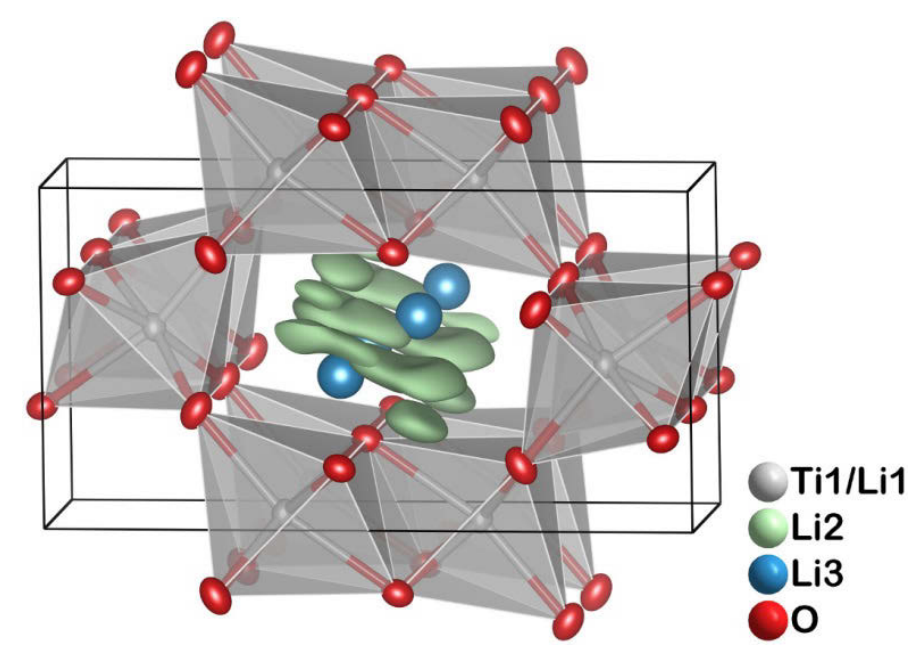

Fig. 3. Detail of the crystal structure of $\mathrm{Li}_{2} \mathrm{Ti}_{3} \mathrm{O}_{7}$ at $24{ }^{\circ} \mathrm{C}$. View approximately along $b$, Li2 as PDF isosurface of $0.1 \times 10^{-6} \mathrm{pm}^{-3}$, other ions as spheres and ellipsoids of $50 \%$ probability, unit cell in black.

The r.t. models acquired from neutron and X-ray diffraction (cf. Supporting Information, section 2) are reconcilable. It should be noted that, in the case of X-rays, the absolute values of the isotropic displacement parameters suffer from strong correlation with the roughness correction and cannot be 
compared with those derived from neutron measurements. Astonishingly, the occupation factors of lithium ions are qualitatively reproduced (high for Li2, low for Li3, very low for Li1), in spite of lithium being a notoriously weak X-ray scatterer.

Judging from the $R$ values of refinements on neutron data (see Table 1), the quality of fit decreases with rising temperature. We attribute this to dynamic disorder of the interstitial lithium ions, i.e., thermally activated lithium-ion diffusion. We have failed to adequately describe their complex distribution at $201^{\circ} \mathrm{C}$ and above with any classical model more sophisticated then isotropic displacement. This resulted in an increase of the modulus of residual SLD in the interstitial, which is furthermore far from featureless. In accordance, the reconstructed lithium content (including only the positions Li1, $\mathrm{Li} 2$, and Li3) decreases with temperature, so that above $400{ }^{\circ} \mathrm{C}$ only slightly more than $75 \%$ of the nominal value was found (evaporation of lithium oxide can be ruled out as a reason, because all measurements were conducted far below its boiling and melting point and the vanadium container was tightly sealed). Additionally, strong correlations between the isotropic displacement parameters of Li2 and Li3 occurred: if the site occupation factor (s.o.f.) of one was artificially lowered, the other one compensated for it by coordinate shifts, an increased s.o.f. and isotropic displacement.

In the refinement of the data acquired at $612{ }^{\circ} \mathrm{C}$, additional irregularities ensued. These include markedly different orientations of the displacement ellipsoids and unexpected changes in bond lengths of Ti1 and 02, as well as a change of the coordination polyhedron for Li3 from distorted tetrahedral to distorted trigonal/trigonal-bipyramidal ( $c f$. Table S2). Because of the ambiguity between fast lithium diffusion and the onset of decomposition, we consider it unsound to attribute the irregularities to either of them and refrain from discussing this dataset in inappropriate detail.

In summary, we found a nontrivial lithium ion distribution in the channels of ramsdellite-like $\mathrm{Li}_{2} \mathrm{Ti}_{3} \mathrm{O}_{7}$ at r.t. When increasing the temperature to $422^{\circ} \mathrm{C}$, thermally activated diffusion leads to a rather flat distribution that cannot be handled adequately by established models. As this hindered rigorous evaluation of activation barriers [44, 45], we were interested in finding out about the plausibility of lithium migration mechanisms already proposed for elevated temperatures.

\subsection{Topological Analyses}

Topological analyses offer such insight and provide ample more information than crystal-chemical rules of thumb. For a first assessment, we chose analysis of the procrystal void surface, which had already proven its value with potential ion conductors [45-47]. To model a channel with intact boundaries as well as one with an adjacent framework vacancy, we set up an ordered $2 \times 2 \times 2$ supercell with no lithium and nearly full titanium occupation $\left(\mathrm{Ti}_{31} \mathrm{O}_{64}{ }^{4-}\right)$. Note that the ion positions are derived from a space- and time-averaged structure, which is locally unrelaxed and does thus not represent a state of thermodynamic equilibrium.

At $422^{\circ} \mathrm{C}$, a void surface exists for procrystal densities of $\rho_{\text {pro }} \geq 0.0045$ a.u., showing isolated cusps in the tetrahedral voids of the structure. For $\rho_{\text {pro }} \geq 0.005$ a.u., these cusps connect to ribbons running along $b$. The framework defect is also visible at this isovalue, but does not connect to two/three channels below $0.0055 / 0.006$ a.u., respectively (see Fig. 4). At $24{ }^{\circ} \mathrm{C}$, the structure shows the same features for slightly higher isovalues. This is expected, because thermal contraction makes the available voids less spacious. While all these values are somewhat higher than anticipated for a rigid framework [46], they do offer some insight into this well-established ion conductor. Firstly, the broad and featuredeprived ribbons indicate that, from a purely topological point of view, many positions in the channel are available and similarly favorable. Secondly, a possible diffusion between channels would occur 
through framework vacancies (connecting two to three channels), but be disfavored compared to inchannel migration.
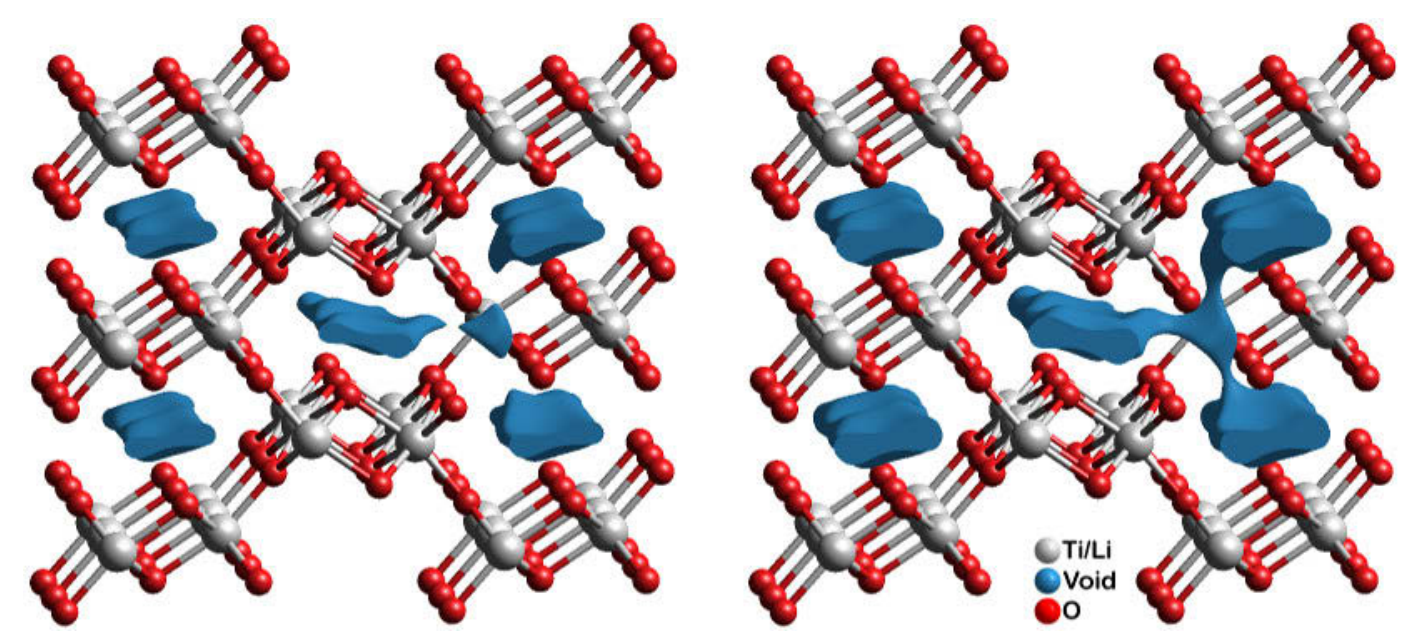

Fig. 4. Procrystal void surface of the $\mathrm{Ti}_{3} \mathrm{O}_{7}{ }^{2-}$ framework at $422^{\circ} \mathrm{C}$ for $\rho_{\text {pro }}=0.005$ a.u. (left) and $\rho_{\text {pro }}=0.006$ a.u. (right). Details showing intact channels on the left and a framework vacancy on the right, ions with arbitrary radii.

The Voronoi-Dirichlet partitioning (VDP) analysis of the framework takes into account the size of migrating ion, elementary voids and channels, as well as the crystal-chemical environment. Therefore, it offers deeper insight into the reasons for (dis-)favoring certain pathways and has already been successfully applied to fast ion conductors [37]. We used the $2 \times 2 \times 2$ supercell model introduced above $\left(422^{\circ} \mathrm{C}\right.$ ) and performed a standard procedure (see section 2.2 ) with slightly relaxed exclusion criteria (necessary spherical-domain radius: $-1.5 \%$ ).

Its consequent application leaves only three kinds of significant voids, all of them situated in the interstitial space (see Fig. 5). They form zig-zag chains along $b$, which are connected pairwise (one pair per channel) to fused six-membered rings. These constitute ribbons that are reminiscent of those found by procrystal analysis. This arrangement shows the most probable, preferred migration path for lithium ions. Interestingly, the positions $\mathrm{Li} 2$ and Li3, as derived from diffraction, are significantly displaced with respect to the nearest elementary void centers. At $24{ }^{\circ} \mathrm{C}$, in contrast, the "well-behaved" Li2 coincides with such a center. The displacement may thus be a reason or an indicator for the refinement problems experienced with classical models. As we were also interested in potential paths between interstitial channels, we included probabilistic (i.e., non-ideal or hindered) elementary voids and channels in the analysis. This left two additional possibilities for the migration of lithium ions (ideal void radius: $R_{\mathrm{sd}}=138 \mathrm{pm}$, ideal channel radius: $R_{\mathrm{ad}}=180 \mathrm{pm}$ ): one path through the center of the edge of a $\mathrm{TiO}_{6}$ octahedron (bottlenecks: $R_{\mathrm{sd}}=131 \mathrm{pm}, R_{\mathrm{ad}}=146 \mathrm{pm}$, significantly determined by cations; furthest hop distance: $r=230 \mathrm{pm})$ and one path through a framework vacancy $\left(R_{\mathrm{sd}}=124 \mathrm{pm}\right.$, $R_{\mathrm{ad}}=165 \mathrm{pm}$, determined only by anions; $r=205 \mathrm{pm}$; see Fig. 5). Even if this vacancy with its $R_{\mathrm{sd}}=124 \mathrm{pm}$ is far too small to permanently host a lithium ion, the path including it is preferred according to all other criteria. 


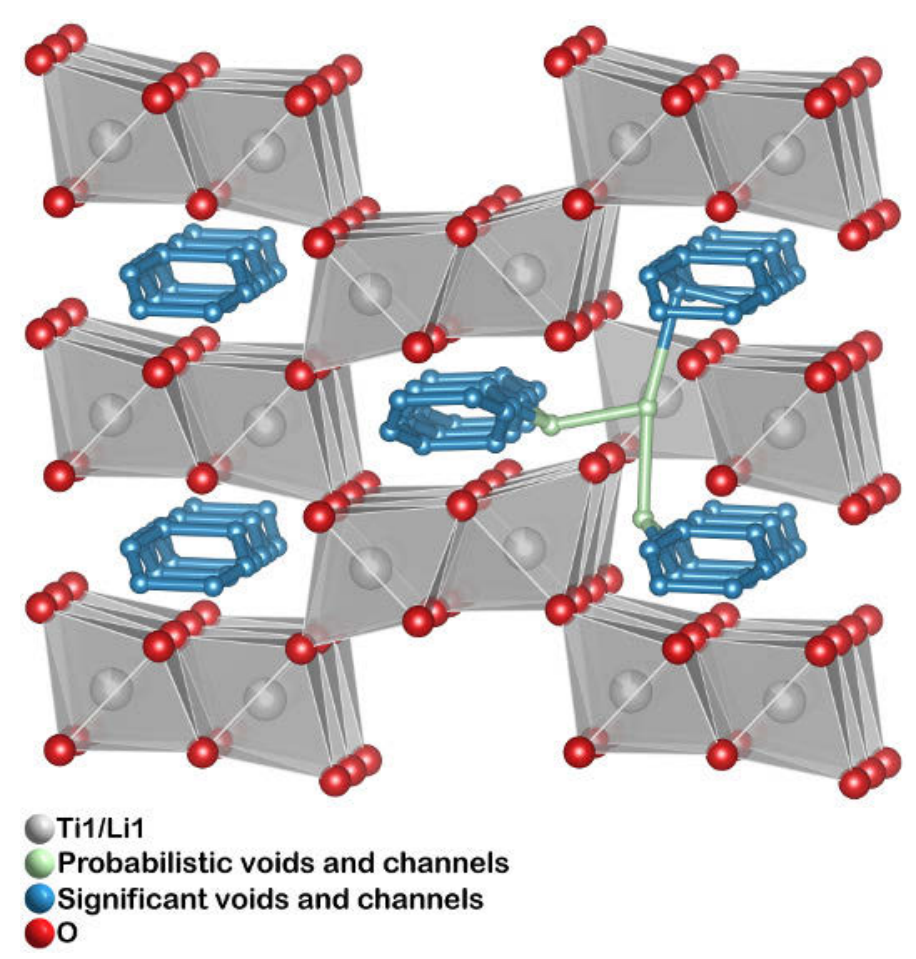

Fig. 5. Void structure of the $\mathrm{Ti}_{3} \mathrm{O}_{7}{ }^{2-}$ framework at $422^{\circ} \mathrm{C}$ as found by VDP analysis. Detail showing intact channels on the left and a framework vacancy on the right; ions, void centers, and channels with arbitrary radii.

In summary, the topological analyses corroborate a preference for diffusion in the channels along $b$. The most probable path between these channels-for reasons of size and chemical environmentincludes framework vacancies. As it is however still disfavored and framework vacancies are less frequent than interstitial vacancies, conduction along $a$ and $c$ is indeed expected to be much less efficient than along $b$.

\subsection{Scattering-Length Density Distributions}

After having evaluated the probability of suggested diffusion pathways, we wanted to check if the data acquired from diffraction experiments indeed corroborate our findings. For this purpose, we had a closer look at the SLD distribution within the unit cell. Unfortunately, traditionally constructed distributions (via Fourier synthesis from structure factors) suffer from noise and termination artifacts. To overcome this, we employed MEM, which is a versatile approach to the estimation of a model from a limited amount of information by maximizing information entropy under constraints consistent with observed physical quantities [48]. In the crystallographic case, MEM gives the maximum variance of calculated structure factors within standard deviations of observed structure factors and has already become a well-established technique in the visualization of lithium diffusion pathways $[49,50]$, even for lower-quality datasets [51].

MEM reconstruction led to physically sensible results with good fits to the data, although the one at $612{ }^{\circ} \mathrm{C}$ is of somewhat lower quality ( $c f$. Table S5). Inspection of plots for high-SLD isosurfaces showed that atomic positions are reproduced with some deviation for the interstitial lithium ions (especially Li3). Unfortunately, both of the present cations exhibit negative scattering lengths in their natural mixture (Li: $-1.90[2] \mathrm{fm}$, Ti: $-3.370[13] \mathrm{fm}$ ) [52]; and not only is titanium the stronger scatterer, but also more abundant in this compound. It is, however, safe to assume that interstitial negative SLD is only caused by lithium ions, as titanium(IV) ions are immobile. 
In isosurface plots (see Fig. 6) at $24^{\circ} \mathrm{C}$, the ribbons suggested by topological methods are discernible. At $201{ }^{\circ} \mathrm{C}$, however, they disconnect to form isolated blobs stretching along $a$. At even higher temperatures, smearing is observed until, at $612{ }^{\circ} \mathrm{C}$, small arms of SLD stretch out from the framework positions towards the channels. This suggests that the structure at r.t. is indeed a statically disordered "snapshot" of the fluctuating structure during synthesis at $1050^{\circ} \mathrm{C}$. On heating, it relaxes by depopulating energetically less favored lithium positions in the channels (disconnection). Further heat again increases thermal displacement (smearing) until framework positions may actually be involved (arms). We understand this very last point as a mere hint, as the model at $612^{\circ} \mathrm{C}$ is not of the same quality as those below this temperature (vide supra).
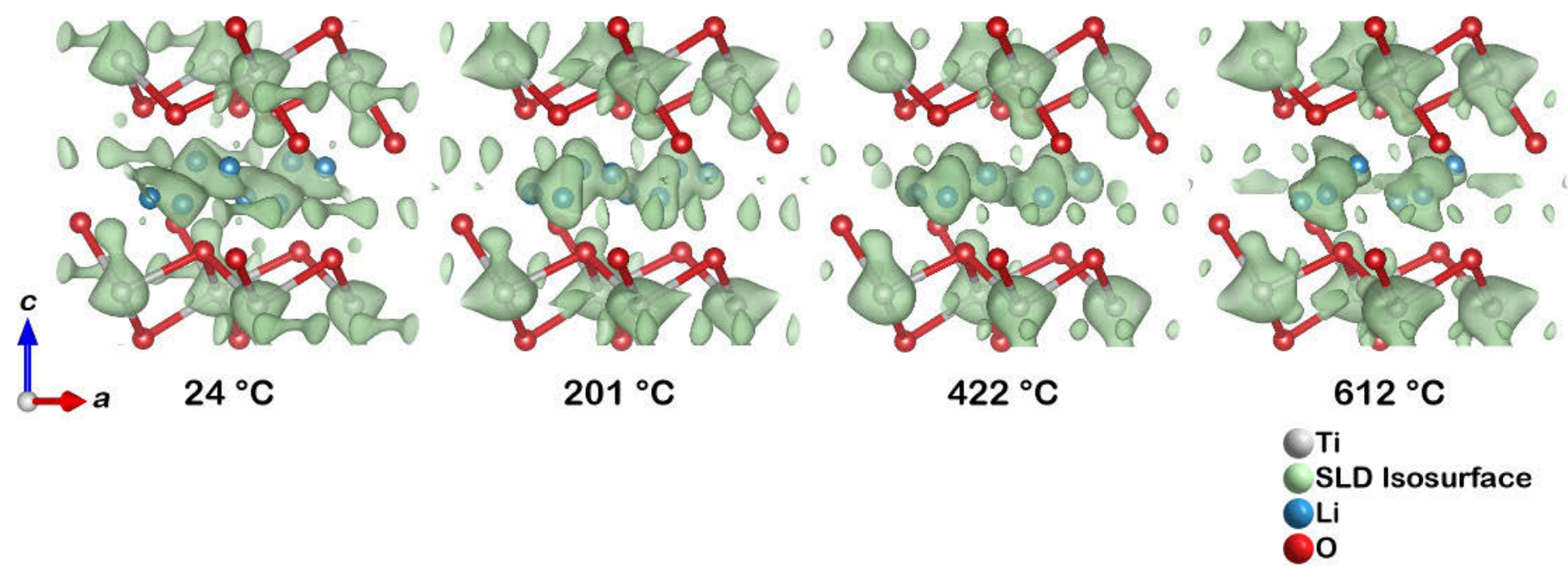

Fig. 6. Details of the crystal structure of $\mathrm{Li}_{2} \mathrm{Ti}_{3} \mathrm{O}_{7}$ at different temperatures with isosurface for scatteringlength density (SLD) of $\rho_{\mathrm{b}}=-0.08 \times 10^{-6} \mathrm{fm} \mathrm{pm}^{-3}$. View approximately along [3 $\overline{10} 0$ ], ions with arbitrary radii.

\section{Conclusions}

In line with contemporary publications, we found further evidence that lithium ions almost exclusively occupy interstitial positions in ramsdellite-like $\mathrm{Li}_{2} \mathrm{Ti}_{3} \mathrm{O}_{7}$. Any minor occupation of the framework cation position is energetically disfavored, metastable, and caused by only few ions arrested during migration at high temperature. Inside the interstitial channels, we did not observe split lithium positions, but a rather broad and flat distribution of negative SLD. This caused problems in refinement of classical discrete-atom models and may be the reason for the fit of split models to comparable datasets.

With respect to lithium occupation, the r.t. structure is most fittingly interpreted as a mostly static "snapshot" of the highly dynamic situation at the synthesis temperature of more than $950{ }^{\circ} \mathrm{C}$. Herein, numerous energetically similar positions are assumed, each with rather low occupancy. Upon heating, the lithium ions become increasingly mobile. This leads from partial relaxation at $201^{\circ} \mathrm{C}$ to additional thermally induced displacement at $422^{\circ} \mathrm{C}$, as witnessed by smearing of negative SLD. At $612{ }^{\circ} \mathrm{C}$, the border of the metastability range is reached: pure ramsdellite-like $\mathrm{Li}_{2} \mathrm{Ti}_{3} \mathrm{O}_{7}$ decomposes slowly, but immediately into spinel-like $\mathrm{Li}_{4} \mathrm{Ti}_{5} \mathrm{O}_{12}$ and rutile, without transforming to (probably dopant-stabilized) hexagonal $\mathrm{Li}_{2} \mathrm{Ti}_{3} \mathrm{O}_{7}$.

Thorough topological analyses of procrystal voids and Voronoi-Dirichlet partitioning of the $\mathrm{Ti}_{3} \mathrm{O}_{7}{ }^{2-}$ framework reveal that migration along zig-zag chains in the channels along $b$ is the strongly preferred 
mechanism for lithium diffusion. Additionally, hops between two chains adjacent in $a$ direction in the same channel are possible. Interchannel transport, on the other hand, is less favored, but may occur through an-albeit less abundant-framework cation vacancy. These findings account for the anisotropy of ionic conductivity that has been found previously: $\sigma_{b} \gg \sigma_{a}>\sigma_{c}$.

\section{Acknowledgements}

The authors would like to thank Marc R. Krey (Leibniz Universität Hannover) for performing ICPOES. We thank HZB for the allocation of neutron radiation beamtime. Financial support by the Deutsche Forschungsgemeinschaft (FOR 1277: "Mobilität von Lithiumionen in Festkörpern [molife]") is gratefully acknowledged.

\section{References}

[1] G.H. Jonker, in: Trabajos de la Tercera Reunión Internacional sobre Reactividad de los Sólidos, Consejo Superior de Investigaciones Científicas (CSIC), Madrid, 1957, pp. 413-421.

[2] M. Lundberg, S. Andersson, Acta Chem. Scand. 18 (1964) 817.

[3] B. Morosin, J.C. Mikkelsen Jr., Acta Crystallogr., Sect. B: Struct. Crystallogr. Cryst. Chem. 35 (1979) 798-800.

[4] A.M. Byström, Acta Chem. Scand. 3 (1949) 163-173.

[5] L.A.H. MacLean, F.L. Tye, Acta Chem. Scand. 49 (1995) 467-468.

[6] J. Lima-de-Faria, E. Hellner, F. Liebau, E. Makovicky, E. Parthé, Acta Crystallogr., Sect. A: Found. Crystallogr. 46 (1990) 1-11.

[7] S. Kikkawa, F. Yasuda, M. Koizumi, Mater. Res. Bull. 20 (1985) 1221-1227.

[8] K. Chiba, N. Kijima, Y. Takahashi, Y. Idemoto, J. Akimoto, Solid State Ionics 178 (2008) 17251730.

[9] J.C. Mikkelsen Jr., J. Am. Ceram. Soc. 63 (1980) 331-335.

[10] P. Bordet, C. Bougerol Chaillout, I.E. Grey, J.L. Hodeau, O. Isnard, J. Solid State Chem. 152 (2000) 546-553.

[11] D. Tsubone, M. Iwamoto, T. Shimizu, J. Ceram. Soc. Jpn. 100 (1992) 791-796.

[12] A. Orera, M.T. Azcondo, F. García-Alvarado, J. Sanz, I. Sobrados, J. Rodríguez-Carvajal, U. Amador, Inorg. Chem. 48 (2009) 7659-7666.

[13] D. Tang, C.M. Teng, J. Zou, F.H. Li, Acta Crystallogr., Sect. B: Struct. Sci. 42 (1986) 340-342.

[14] R.K.B. Gover, J.T.S. Irvine, J. Solid State Chem. 141 (1998) 365-372.

[15] L. Aldon, M. Van Thournout, P. Strobel, O. Isnard, J. Olivier-Fourcade, J.C. Jumas, Solid State Ionics 177 (2006) 1185-1191.

[16] A. Laumann, H. Boysen, M. Bremholm, K.T. Fehr, M. Hoelzel, M. Holzapfel, Chem. Mater. 23 (2011) 2753-2759. 
[17] I. Abrahams, P.G. Bruce, W.I.F. David, A.R. West, J. Solid State Chem. 78 (1989) 170-177.

[18] W. Cho, T. Kashiwagi, W. Ra, M. Nakayama, M. Wakihara, Y. Kobayashi, H. Miyashiro, Electrochim. Acta 54 (2009) 1842-1850.

[19] C.J. Chen, M. Greenblatt, Mater. Res. Bull. 20 (1985) 1347-1352.

[20] M.E. Arroyo y de Dompablo, E. Morán, A. Várez, F. García-Alvarado, Mater. Res. Bull. 32 (1997) 993-1001.

[21] M.E. Arroyo y de Dompablo, A. Várez, F. García-Alvarado, J. Solid State Chem. 153 (2000) 132139.

[22] M.M. Islam, P. Heitjans, T. Bredow, J. Phys. Chem. C 120 (2016) 5-10.

[23] J.B. Boyce, J.C. Mikkelsen Jr., Solid State Commun. 31 (1979) 741-745.

[24] S. Hayashi, H. Hatano, J. Ceram. Soc. Jpn. 102 (1994) 378-382.

[25] N. Sakai, K. Toda, M. Sato, F. Kanamaru, Key Eng. Mater. 181 (2000) 167-170.

[26] M. Umeda, K. Tuchiya, H. Kawamura, Y. Hasegawa, Y. Nanjo, Fusion Technol. 39 (2001) 654-658.

[27] P.J. Basser, C. Pierpaoli, J. Magn. Reson., Ser. B 111 (1996) 209-219.

[28] R.G. Buckley, B.P. Clayman, J.C. Mikkelsen Jr., Phys. Rev. B: Condens. Matter Mater. Phys. 26 (1982) 6509-6515.

[29] M. Van Thournout, L. Aldon, M. Womes, B. Ducourant, J. Olivier-Fourcade, C. Tessier, S. Levasseur, J. Power Sources 174 (2007) 1270-1274.

[30] F. Chen, R. Li, M. Hou, L. Liu, R. Wang, Z. Deng, Electrochim. Acta 51 (2005) 61-65.

[31] A. Franz, A. Hoser, J. Large-Scale Res. Facil. (2016), submitted.

[32] V. Petříček, M. Dušek, L. Palatinus, Z. Kristallogr. - Cryst. Mater. 229 (2014) 345-352.

[33] P. Thompson, D.E. Cox, J.B. Hastings, J. Appl. Crystallogr. 20 (1987) 79-83.

[34] J.-F. Bérar, G. Baldinozzi, J. Appl. Crystallogr. 26 (1993) 128-129.

[35] S.K. Wolff, D.J. Grimwood, J.J. McKinnon, M.J. Turner, D. Jayatilaka, M.A. Spackman, CrystalExplorer 3.1 - Crystal Structure Analysis with Hirshfeld Surfaces, University of Western Australia, Perth (Australia), 2012.

[36] V.A. Blatov, A.P. Shevchenko, D.M. Proserpio, Cryst. Growth Des. 14 (2014) 3576-3586.

[37] V.A. Blatov, G.D. Ilyushin, O.A. Blatova, N.A. Anurova, A.K. Ivanov-Schits, L.N. Dem'yanets, Acta Crystallogr., Sect. B: Struct. Sci. 62 (2006) 1010-1018.

[38] K. Momma, T. Ikeda, A.A. Belik, F. Izumi, Powder Diffr. 28 (2013) 184-193.

[39] F. Izumi, K. Momma, IOP Conf. Ser.: Mater. Sci. Eng. 18 (2011) 022001.

[40] K. Brandenburg, Diamond 4.1 - Crystal and Molecular Structure Visualization, Crystal Impact - H. Putz \& K. Brandenburg GbR, Bonn (Germany), 2015.

[41] K. Momma, F. Izumi, J. Appl. Crystallogr. 44 (2011) 1272-1276. 
[42] OriginLab, OriginPro 2016 - Data Analysis and Graphing Software, OriginLab Corp., Northampton (USA), 2016.

[43] W.K. Pang, V.K. Peterson, N. Sharma, J.-J. Shiu, S.-h. Wu, Chem. Mater. 26 (2014) 2318-2326.

[44] D. Wiedemann, M.M. Islam, S. Nakhal, A. Senyshyn, T. Bredow, M. Lerch, J. Phys. Chem. C 119 (2015) 11370-11381.

[45] D. Wiedemann, S. Nakhal, J. Rahn, E. Witt, M.M. Islam, S. Zander, P. Heitjans, H. Schmidt, T. Bredow, M. Wilkening, M. Lerch, Chem. Mater. 28 (2016) 915-924.

[46] M.Ø. Filsø, M.J. Turner, G.V. Gibbs, S. Adams, M.A. Spackman, B.B. Iversen, Chem. Eur. J. 19 (2013) 15535-15544.

[47] S. Nakhal, D. Wiedemann, B. Stanje, O. Dolotko, M. Wilkening, M. Lerch, J. Solid State Chem. 238 (2016) 60-67.

[48] F. Izumi, Solid State Ionics 172 (2004) 1-6.

[49] A. Senyshyn, H. Boysen, R. Niewa, J. Banys, M. Kinka, Y. Burak, V. Adamiv, F. Izumi, I. Chumak, H. Fuess, J. Phys. D: Appl. Phys. 45 (2012) 175305.

[50] M. Yashima, J. Ceram. Soc. Jpn. 117 (2009) 1055-1059.

[51] D. Wiedemann, S. Indris, M. Meven, B. Pedersen, H. Boysen, R. Uecker, P. Heitjans, M. Lerch, Z. Kristallogr. - Cryst. Mater. 231 (2016) 189-193.

[52] V.F. Sears, in: E. Prince (Ed.) International Tables for Crystallography, 3rd ed., Kluwer Academic Publishers, Dordrecht (Netherlands), 2004, pp. 444-454. 